\title{
The Universal Cloud and Aerosol Sounding System (UCASS): a low-cost miniature optical particle counter for use in dropsonde or balloon-borne sounding systems
}

\author{
Helen R. Smith ${ }^{1, \mathrm{a}}$, Zbigniew Ulanowski ${ }^{1, \mathrm{~b}}$, Paul H. Kaye ${ }^{1}$, Edwin Hirst ${ }^{1}$, Warren Stanley ${ }^{1}$, Richard Kaye ${ }^{1}$, \\ Andreas Wieser $^{2}$, Chris Stopford ${ }^{1}$, Maria Kezoudi ${ }^{1}$, Joseph Girdwood $^{1}$, Richard Greenaway ${ }^{1}$, and Robert Mackenzie ${ }^{1}$ \\ ${ }^{1}$ Centre for Atmospheric and Climate Physics Research, School of Physics Astronomy and Maths, \\ University of Hertfordshire, Hatfield, Hertfordshire, UK \\ ${ }^{2}$ Institute of Meteorology and Climate Research, Karlsruhe Institute of Technology, 76021 Karlsruhe, Germany \\ anow at: TruLife Optics Ltd, 79 Trinity Buoy Wharf, London, UK \\ ${ }^{b}$ now at: Centre for Atmospheric Science, SEES, University of Manchester, Manchester, UK
}

Correspondence: Zbigniew Ulanowski (joe.ulanowski@yahoo.com)

Received: 21 February 2019 - Discussion started: 11 March 2019

Revised: 25 September 2019 - Accepted: 12 October 2019 - Published: 13 December 2019

\begin{abstract}
A low-cost miniaturized particle counter has been developed by The University of Hertfordshire (UH) for the measurement of aerosol and droplet concentrations and size distributions. The Universal Cloud and Aerosol Sounding System (UCASS) is an optical particle counter (OPC), which uses wide-angle elastic light scattering for the high-precision sizing of fluid-borne particulates. The UCASS has up to 16 configurable size bins, capable of sizing particles in the range $0.4-40 \mu \mathrm{m}$ in diameter. Unlike traditional particle counters, the UCASS is an open-geometry system that relies on an external air flow. Therefore, the instrument is suited for use as part of a dropsonde, balloon-borne sounding system, as part of an unmanned aerial vehicle (UAV), or on any measurement platform with a known air flow. Data can be logged autonomously using an on-board SD card, or the device can be interfaced with commercially available meteorological sondes to transmit data in real time. The device has been deployed on various research platforms to take measurements of both droplets and dry aerosol particles. Comparative results with co-located instrumentation in both laboratory and field settings show good agreement for the sizing and counting ability of the UCASS.
\end{abstract}

\section{Introduction}

Atmospheric aerosols are a key component in the Earth's radiative system as they modify the local and planetary albedo by way of direct and indirect effects. Aerosols directly impact the radiation budget via the scattering and absorption of solar radiation and, to a lesser extent, the scattering, absorption and emission of terrestrial radiation ( $\mathrm{Li}$ et al., 2010; Zhou and Savijärvi, 2014). At the top of the atmosphere (TOA), global average annual mean radiative forcing due to direct aerosol effects is estimated at $-0.35(-0.85$ to +0.15$) \mathrm{W} \mathrm{m}^{-2}$ (Myhre et al., 2013). Indirect effects arise from aerosols acting as cloud condensation nuclei $(\mathrm{CCN})$ or ice nuclei (IN), thus influencing the formation and evolution of clouds (Twomey, 1977). Measurements from satellites observe the cloud radiative effect (CRE) to be $-50 \mathrm{~W} \mathrm{~m}^{-2}$ in the short wave and $+30 \mathrm{~W} \mathrm{~m}^{-2}$ in the long wave, with estimates varying by $10 \%$ (Loeb et al., 2009). The significant uncertainties of both direct and indirect effects, combined with the subsequent rapid adjustments and feedbacks, prompted the 2013 Intergovernmental Panel on Climate Change (IPCC) to cite aerosol-radiation effects (ARE) and aerosol-cloud interactions as the largest sources of uncertainty in predicting climate change today (IPCC, 2013). The uncertainties stem from a range of causes, including the inadequate characterization of aerosol optical properties, the inaccurate representation of their spatial and temporal cov- 
erage, and the complex nature of interactions between cloud and aerosol (Ramanathan et al., 2001; Twomey, 1977; Charlson et al., 2001; Storelvmo, 2012).

To constrain uncertainties, a varied approach to aerosol measurement is required. To cover large geographical scales, there exists an array of measurements from ground-based sun photometer networks (Holben et al., 1998; Che et al., 2009; Bokoye et al., 2002) to satellite-based instruments (Huete, 2004; Chu et al., 2003; Kaufman et al., 1997; Zhang and Christopher, 2003; Jiao et al., 2018). This combination of instruments provides near-continuous measurements worldwide and yields direct measurements of aerosol properties, such as aerosol optical depth (AOD), and inferred properties, such as number concentration and size distribution. This large-scale coverage is crucial in capturing the spatial extent of atmospheric aerosol, and the continuous nature permits the monitoring of long-term diurnal, seasonal and annual trends. However, there exist considerable discrepancies between satellite products due to uncertainties in calibration, assumed aerosol microphysics, sampling and cloud screening (Kokhanovsky et al., 2010).

Many model studies have demonstrated the sensitivity of ARE to the aerosol layer height (Vuolo et al., 2014; Mishra et al., 2015), thus highlighting the need to accurately represent the vertical distribution of aerosol in global models, which remains a serious challenge. Therefore, in situ studies are necessary for obtaining high-quality, comprehensive datasets for the microphysical characterization of aerosol, the testing of retrieval algorithms and the quality assurance of remote sensing data. Vertically resolved in situ data are typically gathered with aircraft-based instrumentation during research campaigns. These campaigns employ a variety of instruments for particle measurement: from single-scattering particle probes for the counting and sizing of small particles, optical array probes for the imaging of larger particles, and filters to collect samples for in-depth chemical analysis. Despite this assemblage of techniques, there remain deficiencies in the extent to which they can be reasonably deployed. Aircraft campaigns are expensive and subject to accessibility issues (such as airspace restrictions and remoteness), thus limiting the temporal and spatial coverage of any campaign. Whilst co-located remote and in situ measurement campaigns are invaluable for the validation of retrieval algorithms, the coverage of in situ measurements remains limited. Alternative height-resolved in situ measurement techniques are required to bridge this gap between the comprehensive but spatially limited aircraft campaigns and the expansive remote sensing networks. Progress has been made in recent years through the miniaturization of instrumentation. The reduction in weight and size allows instruments to be used on alternative platforms such as weather balloons and unmanned aerial vehicles (UAVs), and, as such, various miniature optical particle counters (OPCs) for balloon-based studies have been developed. For the smaller size range, the Printed Optical Particle Spectrometer (POPS) (Gao et al., 2016) utilizes a blue laser for the counting and sizing of particles from 140 to $3000 \mathrm{~nm}$, making it suitable for $\mathrm{PM}_{2.5}$ measurements. For larger particles, the Cloud Particle Sensor (CPS) uses a $790 \mathrm{~nm}$ laser for the sizing of particles between 2 and $80 \mu \mathrm{m}$ (Fujiwara et al., 2016). The Light Optical Aerosol Counter (LOAC) covers a wide size range from 0.2 to $100 \mu \mathrm{m}$ using a $650 \mathrm{~nm}$ laser. The LOAC takes measurements of scattered intensity at two angular ranges, which are used to determine size and estimate the refractive index of the scattering particle (Renard et al., 2016).

This paper discusses a novel instrument, the Universal Cloud and Aerosol Sounding System (UCASS): a lowcost, lightweight ( $280 \mathrm{~g}$ ), open-path optical particle counter (OPC), designed for use as a dropsonde or as part of a balloon-borne sounding system. Whilst other balloon-based instrumentation exists, the UCASS is the first (to the best of our knowledge) particle counter designed for dropsondebased systems. The UCASS offers the ability to incorporate particle measurements into these soundings, providing vertically resolved measurements of aerosol and droplet concentrations and size distributions. The UCASS may be used as both a dropsonde or upsonde and can therefore provide complementary data to aircraft-based campaigns. The use as a dropsonde is of particular benefit as the aircraft can drop the sondes through a specific air mass, allowing for more targeted measurements. Furthermore, due to the relative ease and affordability of radiosoundings, the UCASS also offers an alternative to aircraft-based measurements with fewer time and space restrictions.

\section{Instrument design}

\subsection{Assembly and optical setup}

For ease of reading, the following section defines a common coordinate system for Figs. 1-4. Furthermore, we define a common set of identifiers, where alphanumeric labelling is used to identify physical parts and roman numerals are used to identify scenarios or alternative views (within the coordinate system). The structural components of the UCASS, shown in Fig. 1, are made primarily from 3-D printed parts. The design is essentially tubular, $180 \mathrm{~mm}$ long and $64 \mathrm{~mm}$ in diameter. An elliptical cross section hole, $30 \mathrm{~mm} \times 22 \mathrm{~mm}$ in size, runs the full length of the UCASS body and offers a low impedance path for the sample flow, defined as the $-y$ direction in the instrument coordinate system. The UCASS is designed with this particular shape for use as a dropsonde system, whereby a connected KITsonde fits inside the UCASS and the entire payload fits within a standard release container. This is discussed further in Sect. 3.2.1. The main unit (a1) is 3-D printed from nylon using selective laser sintering (SLS). This process is chosen for the main unit as it produces a mechanically rigid and thermally stable chassis, which is crucial for the instrument to endure the temperature cycle associated 


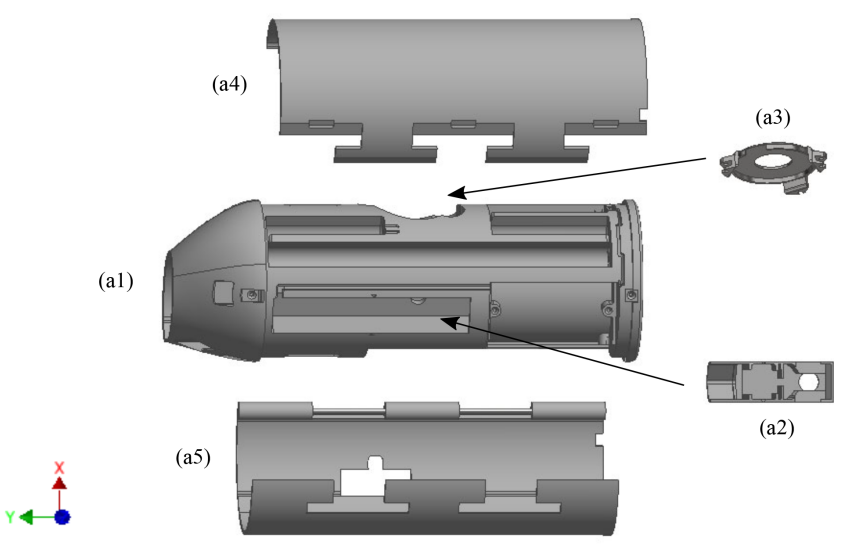

Figure 1. Structural components of the UCASS. This consists of four 3-D printed components: the main housing unit (a1), inserts for the beam-forming optics (a2) and the outer casing (a4) and (a5). The mirror holder (a3) is machined out of aluminium.

with a routine sounding. The process uses a layer thickness of $0.12 \mathrm{~mm}$, which is adequate for the placement of mechanical components such as batteries and circuitry. However, to improve the precision for optical components, a modular design is used, thus allowing each optical element to be aligned and secured individually. The beam-forming optics are mounted onto an insert (a2), which is 3-D printed from polylactic acid (PLA) using fused filament fabrication (FFF). This method is chosen for increased mechanical rigidity, which is required for the thin wall thicknesses. The elliptical mirror is mounted on an aluminium insert (a3), which is machined using a fiveaxis mill. Once the beam-forming optics are aligned, the insert (a2) is secured into place in the main unit. The elliptical mirror, mounted on insert (a3) is aligned using three adjustment screws, which secure the mirror onto the main unit (a1). Once assembled, the UCASS is enclosed by a 3-D printed sleeve (a4) and (a5).

The optical assembly is shown in Fig. 2. Here, the UCASS chassis (a1) is shown as a transparent layer to illustrate the placement of the optical elements. Figure 2a shows a view along the $x-y$ plane (parallel to the airflow), and Fig. $2 b$ shows a view in the $x-z$ plane (perpendicular to the airflow). The input beam is a $658 \mathrm{~nm}$ continuous-wave diode laser (b1) from Oclaro (part no. HL6501MG), operating at $10 \mathrm{~mW}$. The laser is fitted with a collimator from the Optoelectronics Company (part no. 500-020012). The collimated beam of the elliptical cross section is approximately $3.5 \mathrm{~mm}$ (long axis) by $2 \mathrm{~mm}$ (short axis) and is focused along the short axis by a $50 \mathrm{~mm}$ focal length cylindrical lens (b2) from Edmund Optics (part no. 68-047) and then passes through a $2 \mathrm{~mm}$ aperture (b3) perpendicular to the beam's long axis. For ease of assembly, these beam-forming components (parts b1, b2 and b3 in Fig. 2) are mounted onto an insert (part a2 in Fig. 1). A plane $9 \mathrm{~mm} \times 9 \mathrm{~mm}$ front silvered mirror (b4) (a)

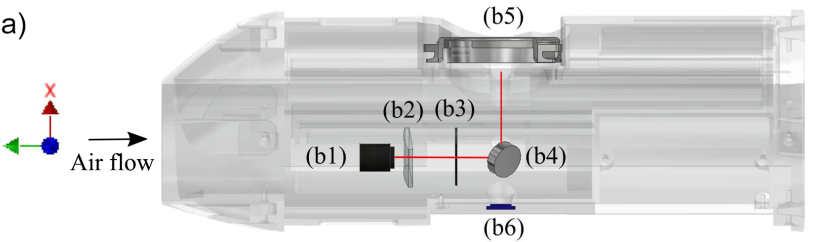

(b)

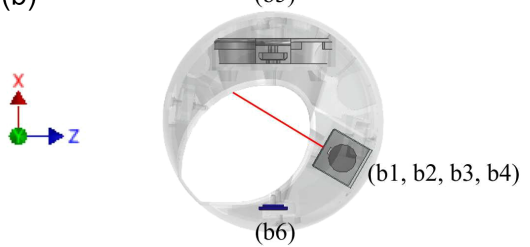

(b1) $658 \mathrm{~nm}$ laser diode (b2)Cylindrical lens (b3) Aperture

(b4)Front silvered mirro (b5) Elliptical mirror (b6) Photodiode detector

Figure 2. Optical assembly of the UCASS. Panel (a) shows a view in the $x-y$ plane, parallel to the airflow. Panel (b) shows a view in the $x-z$ plane, perpendicular to the airflow. The beam-forming optics consist of a laser with collimator (b1), a cylindrical lens (b2) and a $2 \mathrm{~mm}$ aperture (b3). The beam is directed into the instrument via a front silvered mirror (b4), angled at $45^{\circ}$ to the beam. Particles that cross the laser beam will scatter light. The elliptical mirror (b5) collects light scattered between angles 16 and $104^{\circ}$ and focuses this onto the detector (b6), where the pulse height and duration is recorded.

from Edmund optics (part no. 31-004) reflects the beam at $45^{\circ}$, directing it across the flow of air through the UCASS body, it is then extinguished within the UCASS casing via a cavity coated with absorptive paint. The input beam is shown in red in Fig. 2. The $2 \mathrm{~mm}$ aperture has the effect of reforming the beam's Gaussian intensity profile into an approximate "top hat" profile such that, at the sensing area (coincident with the focal distance of the cylindrical lens), the beam has a relatively uniform intensity cross section of $\approx 2 \mathrm{~mm}$ width by $\approx 40 \mu \mathrm{m}$ depth. Particles passing through the beam parallel to its short axis therefore experience similar levels of irradiance, a prerequisite for accurate particle sizing. This is discussed in Sect. 2.2.

Particles carried in the airflow through the UCASS may pass through the laser at any point in its traversal across the air flow path. However, only those passing through a specific $0.5 \mathrm{~mm}^{2}$ sensing area within the laser beam are measured. This sensing area is defined optically by a custom-designed combination of concave elliptical mirror (b5) and a dual-area photodiode detector (b6). Both mirror and detector were designed by the University of Hertfordshire and are now commercially produced by Alphasense Ltd (part no. 836-000100) and First Sensor GmbH (part no. DP12.5-6 SMD), respectively, available only through special order. The elliptical mirror (b5) collects light scattered by a particle passing through the sensing area of the laser beam into a solid angle element of $1.69 \mathrm{sr}$ (scattering angles from 16 to $104^{\circ}$ ) and directs it towards the photodiode detector (b6), where the total intensity is measured. 


\subsection{Particle detection and defining the sensing area}

The photodiode detector, shown in Fig. 3a, is a dualarea design comprised of two electrically isolated photosensitive regions - a central rectangular region measuring $1.9 \mathrm{~mm} \times 1.0 \mathrm{~mm}$, surrounded by a circular region of diameter $4 \mathrm{~mm}$. The design is such that particles that are contained centrally within the sensing area will cause scattered light to be focused onto the inner detector only, whereas particles passing immediately outside of the sensing area will cause the scattered light to be focused onto the outer detector, thus allowing the sample area to be defined optically.

The geometry of the detector, mirror and laser are used to define the sensing area. As shown in Fig. 3ii, the focal point of the laser beam is located at the primary focus of the elliptical mirror and the detector is centred at the secondary focus. The inner detection area is a rectangle, where the width, $w$, directly governs the length of the laser beam (along the beam axis) in which a particle can be detected - and therefore defines one dimension of the sensing area. Figure 4 shows a rotated view of Fig. 3b, this time viewed in the direction of the air flow (the $y$ axis). The image is also rotated slightly around the $z$ axis in order to show the image formed on the detector. Figure $4 \mathrm{a}-\mathrm{c}$ show how the width, $w$, of the inner detector governs the length of the sensing area in the $z$ axis. In this direction, particles passing through the primary focus of the elliptical mirror will cause scattered light to be focused at the secondary focus. However, only those passing within $\pm \frac{1}{2} w$ of the centre of the sensing area will be focused onto the inner detector, whereas particles passing to the left or right will cause light to be focused onto the outer detector (as shown in Fig. 4c) and will not be counted. Figure 4d and e show how the focus of the elliptical mirror is used to define the dimension of the sensing area along the $y$ axis. Particles passing above or below the primary focus of the mirror will cause scattered light to be focused above or below the detector - causing an enlarged image to form on the detector. In the current arrangement, particles passing $0.15 \mathrm{~mm}$ above or below the primary focus will create an image large enough to illuminate both the inner and outer detector, as shown in Fig. 4e, at which point the particle is considered to be outside of the sensing area. This distance is governed by the geometry of the mirror and the size of the inner detector. For particles straddling the boundary of the sensing volume, light will be focused onto both the inner and outer detectors, and therefore a criterion is defined to determine when the particle should or should not be counted. Based upon the intensity measured by the inner detector $\left(I_{1}\right)$ and the intensity measured by the outer detector $\left(I_{2}\right)$ : if $I_{2} \leq \frac{1}{4} I_{1}$ then the particle is considered to be inside the sensing area. The airflow is perpendicular to the sensing area, and, as such, all particles passing through the sensing area (occupying the $x-z$ plane) will traverse the depth of the laser beam (in the $y$ direction). The depth of the laser beam dictates the length of time the particle spends in the beam but does not dictate the number of particles sampled. We therefore define sample area and not sample volume. The total volume of sampled air is then calculated from the sensing area and the speed of the airflow.

Particles entering the sensing area will pass along the short axis of the focused laser beam (in the $y$ direction) causing a pulse of light to fall on the detector. The width of this pulse is equal to the time of flight (ToF) of the particle across the beam, and the height of this pulse corresponds to the maximum intensity incident upon the detector during this transit. The pulse height depends upon the amount of light scattered by the particle, which is a function of particle size, optical properties and the intensity of the incident light. The pulse height is used to derive particle size, whilst ToF data are stored for data quality assurance. To ensure that the laser beam intensity is consistent across the sample area, the beam is clipped with the use of a $2 \mathrm{~mm}$ aperture, thus minimizing sizing errors due to beam non-uniformity. Figure 5 shows the relative intensity distributions across the major (left) and minor (right) axes. As discussed above, particles passing through the beam at the edges of the major axis will form unfocused images on the detector and therefore will not be counted; only the central $0.3 \mathrm{~mm}$ section of the major axis falls within the sensing area.

\subsubsection{Stray light considerations}

Because the UCASS is an open-geometry instrument, the system is subject to stray light when operated during daylight. This issue is addressed with a two-fold approach. Firstly, the interior of the instrument is coated with a highly absorbing paint (Stuart Semple Black 2.0), which reduces the amount of sunlight reflected down the inlet. Whilst many light-absorbing coatings are highly directional, this paint exhibits high absorbency for direct and glancing angles across the visible and near-infrared wavelength range (the sensitivity range of the detector). This paint drastically reduces the amount of sunlight incident on the detector through reflections off instrument surfaces. However, due to the geometry of the system, sunlight may still directly reach the detector for incident angles $<20^{\circ}$ (relative to the $y$ axis). To account for the remaining stray light, the on-board electronics continuously monitor the background signal. This background signal is removed from each pulse prior to saving, thus removing the effect of stray light.

\subsection{Electronics}

A PIC microcontroller-based (PIC18F27J53) electronic circuit governs the operation of the UCASS and how measurements using the dual-photodiode system are made and recorded. A simplified block diagram of the electronics system is shown in Fig. 6. As described above, the photodiode sensor consists of two photosensitive regions, the inner detector and the outer detector. A particle within the sensing area will cause some scattered light to fall incident on the 
(a)

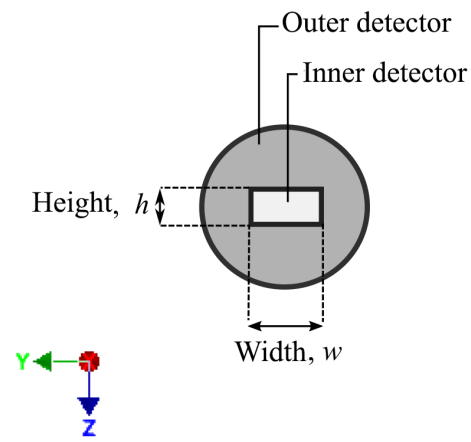

(b)

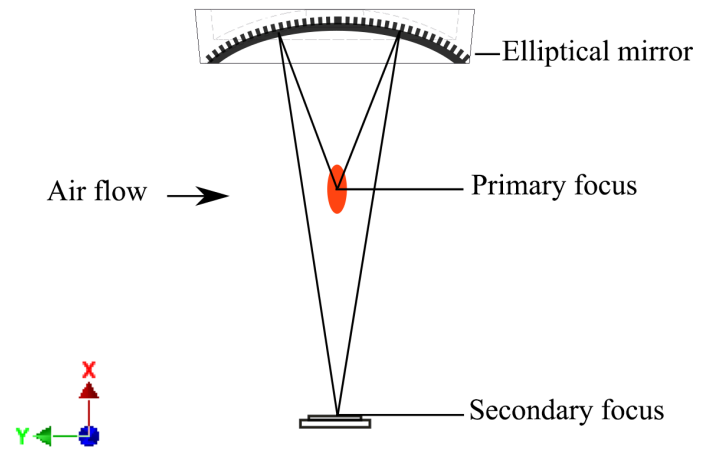

Figure 3. (a) The dual-element detector consists of an inner rectangular detector of width, $w$, and height, $h$. (b) A view of the optical system orthogonal to the air flow: the laser beam is centred on the primary focus of the elliptical mirror, and the detector is centred at the secondary focus. The width, $w$, of the inner detector dictates the length of the laser beam (along the $z$ axis, orthogonal to the air flow) in which a particle can be detected. The height, $h$, of the inner detector is wider than the path of a particle crossing the laser beam and therefore allows the entire pulse caused by a particle transit to be recorded.
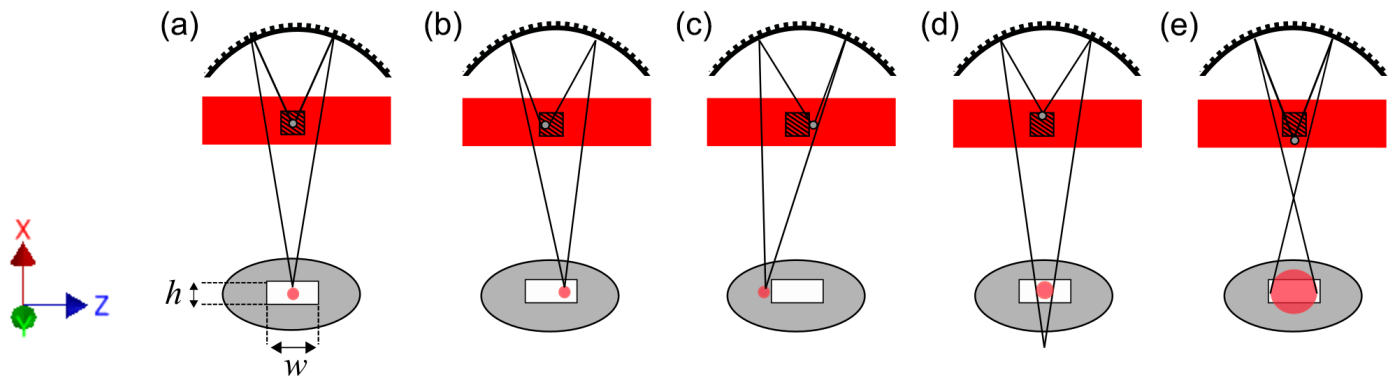

Figure 4. Optically defining the sensing area. The sensing area is shown as a shaded square within the laser beam, particles are represented by grey dots. The airflow direction is in the $y$ direction. (a) Particles passing through the primary focus in the centre of the sensing area cause scattered light to be focused at the centre of the detector. (b) Particles passing to the left or right of the primary focus but still within the sensing area will cause scattered light to be focused to the right or left of the centre of the inner detector. (c) Particles passing more than $\frac{1}{2} w$ to the left or right of the centre of the sensing area will cause scattered light to be focused onto the outer detector. (d) Particles passing above or below the primary focus will cause the scattered light to be focused above or below the secondary focus and therefore above or below the detector, resulting in a larger image on the detector. (e) Particles passing more than $0.15 \mathrm{~mm}$ above or below the primary focus will cause scattered light to fall on both the inner and outer detector. The ratio of the inner and outer detector signals are used to determine whether particles are considered to be in the sensing area.

inner detector, and this inner detector is used to create a trigger. The central element is connected to a circuit that converts the photo current to a voltage ( $0-3.3 \mathrm{~V}$ DC). The background signal is also monitored in order to account for stray light, as discussed in Sect. 2.2.1. The background signal is removed from the measured photocurrent, a process denoted here as "DC restoration". The remaining signal will activate a trigger if the voltage amplitude detected goes above a predefined threshold $(\approx 5 \mathrm{mV})$. In this event, the trigger comparator determines that there is a particle in the sensing area and notifies the core microcontroller. The microcontroller then activates the peak detector electronics that will sample and hold the peak of the light signal on both the inner and outer detectors as the particle passes through the laser beam. Before saving the peak value, a inner and outer signal ratio comparator is used to determine whether the particle is wholly within the sample area (as discussed in Sect. 2.2). If the particle is deemed to be within the sample area, then the microcontroller digitizes both signals with an on-board 12 bit analog-to-digital converter (ADC) and categorizes the combined peak signal into one of 4095 values (based on the resolution of the ADC) dependent upon the size of the amplitude. If the pulse height is too high, the detector will saturate and the particle will not be counted. This would be the case for the upper limit of the detectable size range. If the pulse is too low, the peak signal will not be sufficient to trigger a measurement and the pulse will not be recorded. This would be the case when the particle is below the threshold of the measurable size range.

The measurable size range is determined by the laser power, amplifier gain and detector sensitivity. The amplifier gain can be adjusted by changing resistor values in the 

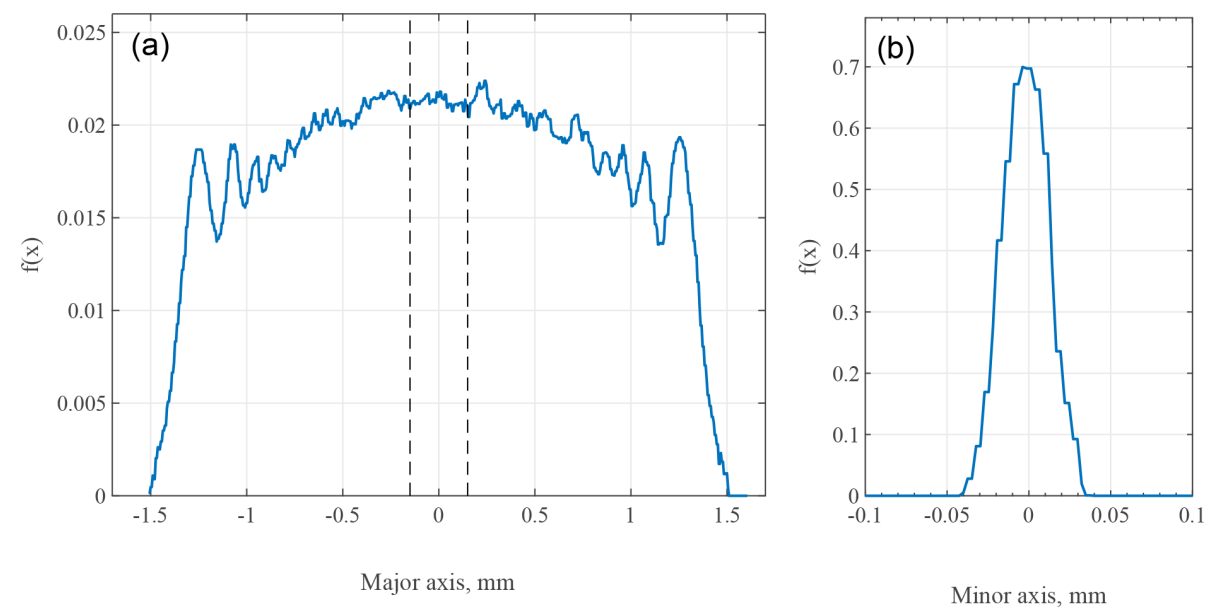

Figure 5. Relative distributions of the laser intensity $f(x)$ across the major (a) and minor (b) axes of the focused laser beam. Only particles passing within the central $0.3 \mathrm{~mm}$ of the major axis (shown as dashed lines) will be considered within the sensing area, and thus only these will be counted.

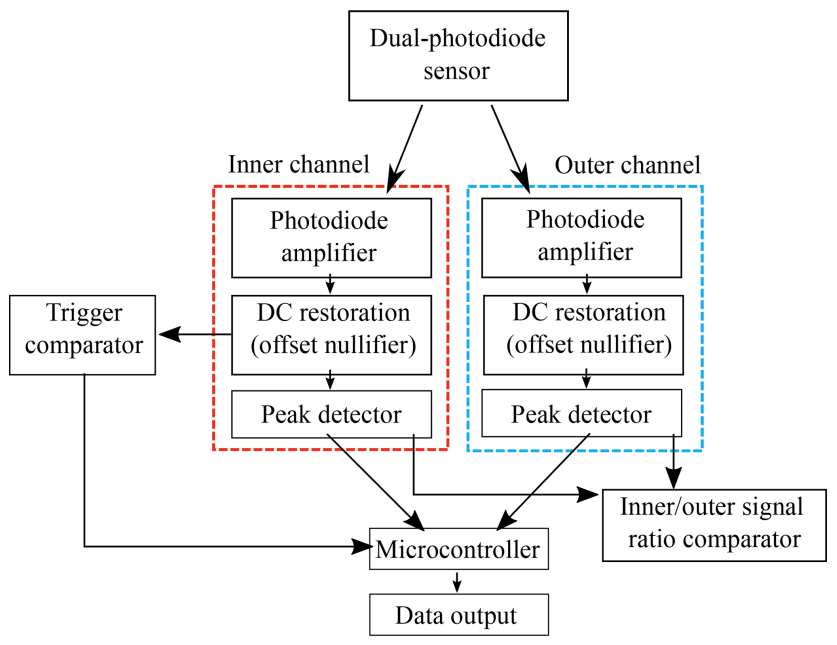

Figure 6. Particles passing through the sensing area will cause light to fall on the inner element of the photodiode sensor. To account for stray light, the background signal is removed, a process labelled here as DC restoration. If the remaining signal on the inner channel goes above a threshold of $5 \mathrm{mV}$, the trigger comparator notifies the microcontroller that there is a particle within the sensing area. The signal's inner and outer channels are then measured to determine the total light incident on the detector (again, the background signal is removed). The inner and outer signal ratio comparator determines whether the particle is wholly inside the sensing area (as discussed in Sect. 2.2), and if the particle is deemed inside the sensing area, the data are saved.

electronic circuit. Two versions of the UCASS hardware are available: a "high-gain" version with a nominal measurable size range of $0.4-17 \mu \mathrm{m}$ and a "low-gain" version with a nominal measurable size range of $1-40 \mu \mathrm{m}$.

Particle-by-particle $(\mathrm{PbP})$ pulse height recording is utilized during instrument calibration (discussed in Sect. 2.4.2); this utilizes all 4095 values of the ADC, allowing the digitized pulse for each particle to be recorded individually. However, during routine measurements, the data are aggregated into fewer size bins, with thresholds and limits defined by the user (up to a maximum of 16 bins). Measurements are rejected if the particle is deemed to be outside of the sample area (as discussed in Sect. 2.2), measurements are also rejected if the ToF is deemed too short or too long. A short ToF would occur if an event such as electrical noise spikes triggered the system. A long ToF would be the case if a large body or agglomeration of particles passed through the beam. The default ToF minimum and maximum limits are 1 and $100 \mu \mathrm{s}$, respectively. As the ToF is a function of particle size (amongst other factors), particles may produce legitimate ToFs above or below the rejection criteria. However, as the UCASS can only measure particles within a specific size range, the ToF rejection criteria are chosen such that particles within the measurable size range cannot realistically produce ToFs outside of the ToF criteria.

In this manner, the microcontroller continuously assembles histograms of particle size and count data. Means of ToF data are also recorded for a subset of the size bins to allow some use of this parameter to monitor flow rate through the device. At every $1 \mathrm{~s}$ interval, the histogram dataset is either saved to an on-board micro SD card or transmitted via a serial link (XDATA protocol) to a radiosonde device for radio frequency (RF) transmission of the data. The histogram data are cleared following each data save and transmit event. The XDATA protocol is limiting in terms of bandwidth, such that there is only space to utilize 10 of the available 16 size bins. The configuration of the bin boundaries can be altered to accommodate this and make best use of the bin quantity available. The device electronics can measure up to $10^{4}$ particles per second and can operate in air flow speeds between 2 and $15 \mathrm{~m} \mathrm{~s}^{-1}$ with the standard firmware. For a standard 
operating velocity of $5 \mathrm{~m} \mathrm{~s}^{-1}$, this equates to a particle concentration of $3.5 \times 10^{9} \mathrm{~m}^{-3}$. The firmware can be modified to change the ToF window, thus allowing shorter or longer particle transitions to be recognized if the measurement platform requires it (this is discussed further in Sect. 3.1). Rather than coincidence, the most significant limit of the counting and sizing system is caused by the dead time of the microcontroller (MCU). This is the time the MCU takes to analyse a particle and increment a count in the appropriate size histogram bin. The system is insensitive to other particles entering the sampling volume during this time. The approximate dead time per particle is $40 \mu$ s processing time plus the particle transit time $(\approx 10 \mu \mathrm{s})$. The $10^{4}$ counts per second rate limit stated is obtained by rounding the transit plus processing time approximation up to $100 \mu$ s and finding the reciprocal. In reality, aerosol is not perfectly homogeneous and particle detection events can be assumed to have a Poisson distribution. Where the counting frequency is significant compared to $10^{4}$ (e.g. $>1000 \mathrm{~s}^{-1}$ ), the proportion of coincidence events to valid events can start to become significant. However, in this research, the peak number concentration is recorded at $\approx 2 \times 10^{7}$, which equates to a counting frequency of $\approx 100$ particles per second. At such counting frequencies the effect of dead-time coincidence is considered negligible.

The size histogram bins utilized by the microcontroller are essentially levels of peak amplitude light signals scattered from measured particles. The bin boundaries are converted into particle diameters based on calibration using both theoretical and experimental data.

\subsection{Calibration}

\subsubsection{Theoretical instrument response}

An OPC directly measures the scattering cross section of a particle. The scattering cross section is a function of the particle properties (size, shape, refractive index), the collection angle of the instrument and the wavelength of the beam (Bohren and Huffman, 1998; Rosenberg et al., 2012). This is defined as follows:

$$
\begin{aligned}
\sigma_{\text {sca }}= & \frac{1}{k^{2}} \int_{0}^{2 \pi} \int_{0}^{\pi} \frac{1}{2}\left[\left|S_{1}\left(\theta, k D_{\mathrm{p}}, n\right)\right|^{2}+\left|S_{2}\left(\theta, k D_{\mathrm{p}}, n\right)\right|^{2}\right] \\
& \sin \theta \omega(\theta, \phi) \mathrm{d} \theta \mathrm{d} \phi,
\end{aligned}
$$

where $\sigma_{\text {sca }}$ is the scattering cross section, $\mathrm{m}^{2}, k$ is the wave number in medium, $\mathrm{m}^{-1}, S_{1}$ and $S_{2}$ are elements of the amplitude scattering matrix representing parallel and polarized light, respectively, $\theta$ is the scattering angle measured from the incident beam direction (rad), $\phi$ is the angle of the scattered light azimuthally around the incident beam (rad), $D_{\mathrm{p}}$ is the diameter of the scattering particle $(\mathrm{m}), n$ is the refractive index of the particle and $\omega$ is the weighting function based on the mirror geometry.
The weighting function can have values between 0 and 1 and describes the azimuthal extent of the collection optics in a finite element $\theta \rightarrow \mathrm{d} \theta$ (Rosenberg et al., 2012). Optical particle counters often use annular reflectors, such as those in the Cloud Droplet Probe (CDP) (Lance et al., 2010) and the Passive Cavity Aerosol Spectrometer Probe (PCASP) (Cai et al., 2013), both by Droplet Measurement Technologies. The weighting function for these instruments can have values of 0 and 1 only. The UCASS utilizes a non-annular reflector in the form of an elliptical mirror centred on a scattering angle of $\theta=60^{\circ}$ with a half angle of $43.8^{\circ}$. The mirror also has a central hole with half angle $10.7^{\circ}$. Using this geometry, the weighting function, $\omega(\theta, \phi)$, is given by

$\omega(\theta, \phi)=\frac{1}{\pi}\left(\phi_{\mathrm{m}}(\theta)-\phi_{\mathrm{h}}(\theta)\right)$,

where $\phi_{\mathrm{m}}$ and $\phi_{\mathrm{h}}$ express the angular extent of the mirror and the hole, respectively, azimuthally around the laser beam as a function of scattering angle, $\theta$. For a primary reflector not centred on $\theta=0^{\circ}, \phi$ is given by

$$
\begin{aligned}
& \phi_{\mathrm{m}, \mathrm{h}}= \\
& \begin{cases}\cos ^{-1}\left[\left(\cos H_{\mathrm{m}, \mathrm{h}}\right.\right. & \\
\left.-\cos L_{\mathrm{m}, \mathrm{h}} \cos \theta\right) & \\
\left./\left(\sin L_{\mathrm{m}, \mathrm{h}} \sin \theta\right)\right] & \text { if }-1<\left(\cos H_{\mathrm{m}, \mathrm{h}}\right. \\
& \left.-\cos L_{\mathrm{m}, \mathrm{h}} \cos \theta\right) \\
& /\left(\sin L_{\mathrm{m}, \mathrm{h}} \sin \theta\right)<1 \\
0 & \text { if }\left(\cos H_{\mathrm{m}, \mathrm{h}}\right. \\
\pi & \left.-\cos L_{\mathrm{m}, \mathrm{h}} \cos \theta\right) \\
& /\left(\sin L_{\mathrm{m}, \mathrm{h}} \sin \theta\right) \geq 1 \\
& \text { if }\left(\cos H_{\mathrm{m}, \mathrm{h}}\right. \\
& \left.-\cos L_{\mathrm{m}, \mathrm{h}} \cos \theta\right) \\
& /\left(\sin L_{\mathrm{m}, \mathrm{h}} \sin \theta\right) \leq-1\end{cases}
\end{aligned}
$$

where $L_{\mathrm{m}, \mathrm{h}}$ is the lens angle of the mirror and hole, respectively, and $H_{\mathrm{m}, \mathrm{h}}$ is the half angle of the mirror and hole, respectively.

Using this weighting function in Eq. (1), we obtain the scattering cross sections as a function of diameter. The matrix elements $S_{1}$ and $S_{2}$ are computed using Jan Schäfer's Mie scattering code "Matscat" (Schäfer, 2011; Schäfer et al., 2012; Bohren and Huffman, 1998; Lee, 1990; Kerker, 1969). Figure 7 shows the scattering cross sections for the materials used in calibration (polystyrene-latex (PSL), borosilicate glass and soda-lime glass) and two typical materials measured with the UCASS (water and mineral dust). Typically for OPCs, the relationship between scattering cross section and geometric diameter is highly non-monotonic due to Mie oscillations, which occur for particles where the size parameter $(\pi \times D / \lambda)$ is larger than $1-2$. Since the Mie oscillations are most prevalent in the forward-scattering region, the wide and side-weighted collection angle of the UCASS elliptical mirror reduces the effect of the oscillations, resulting in a near-monotonic instrument response, as shown in Fig. 7. 


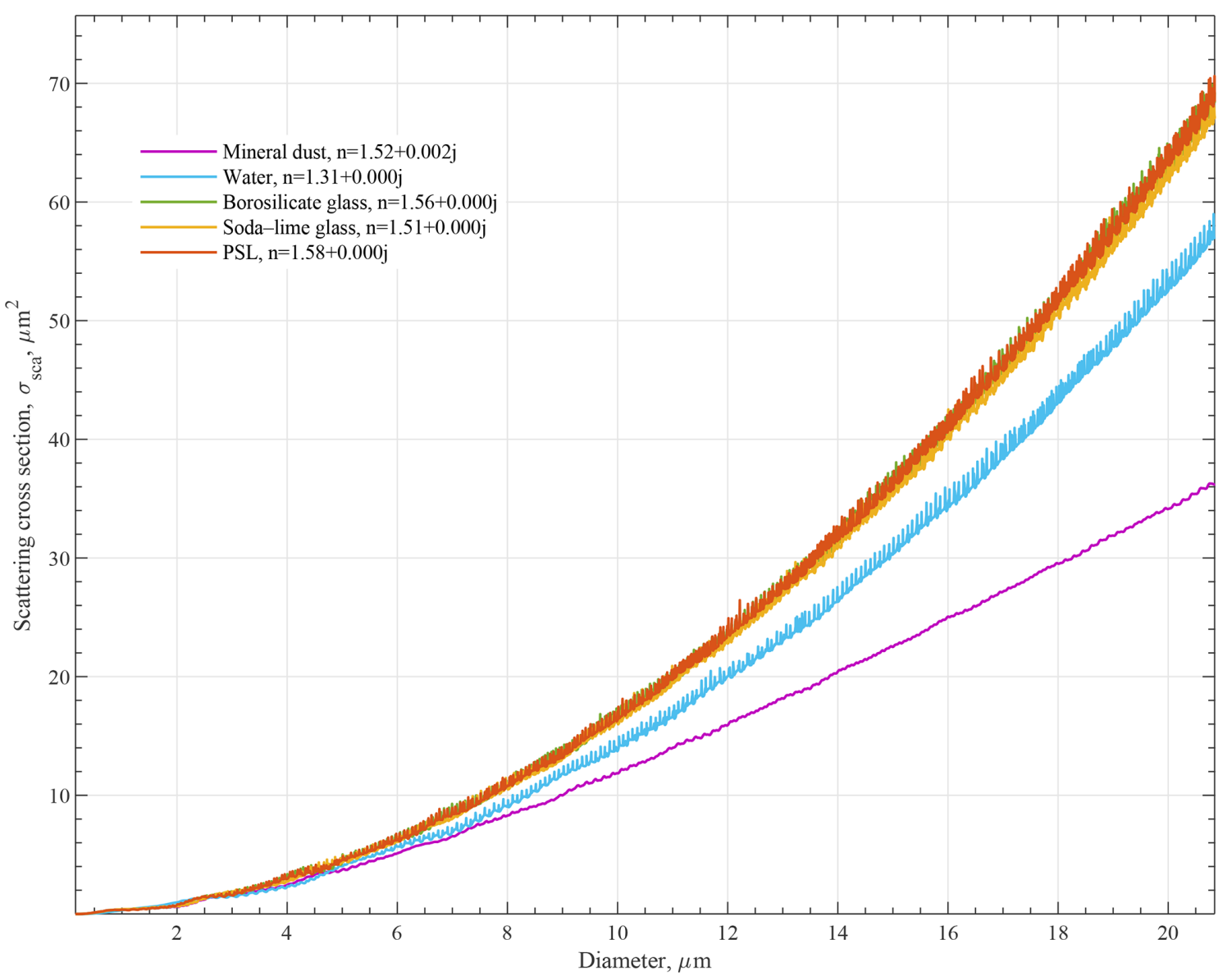

Figure 7. Scattering cross sections, $\sigma_{\mathrm{sca}}$, as a function of geometric diameter for mineral dust, water, borosilicate glass, soda-lime glass and polystyrene-latex (PSL).

For each calibration standard used, the sizing error associated with Mie oscillations falls well within the manufacturerstated standard deviation of the particle size and uncertainties associated with Mie oscillations are not further considered.

The scattering cross section directly describes the amount of light collected by the mirror in the instrument. The instrument response is then a function of scattering cross section, amplifier gain, detector sensitivity and laser power. Variations in the measured output between different units can occur due to manufacturer tolerances in detector sensitivity or laser power, thus causing offsets from the theoretical instrument response. Therefore, to constrain the calibration curve, we combine measured instrument responses with the theoretical results from Mie theory.

\subsubsection{Calibration measurements}

To constrain the calibration curve, we take measurements of the instrument response for a series of National Institute of Standards and Technology (NIST)-traceable particle standards. These include PSL from Polysciences, borosilicate glass from Duke scientific and soda-lime glass from
Whitehouse Scientific. A drying column is used to ensure the proper drying and dispersion of the calibration standards, whilst also establishing a stable, non-turbulent air flow through the UCASS. The experimental setup is shown in Fig. 8. The air intake consists of an initial drying chamber filled with silica gel desiccant, which dries the ambient air before passing it though a high-efficiency particulate air (HEPA) filter. This air is then directed through a series of tubes at the bottom of the drying column, which form a concentric ring around the aerosol input, thus establishing a clean, dry sheath flow into which the aerosol is injected. The purpose of the sheath flow is to accommodate the large volume of air flowing through the instrument. By having a clean, dry sheath flow, calibration particles only need to be contained within the centre of the airflow, allowing them to travel through the sensing area, therefore fewer particles are wasted in the process. The main drying column consists of a $1 \mathrm{~m}$ tall tube with an inner tube for the airflow. The outer tube is packed with silica gel desiccant and the inner tube is lined with a microporous membrane. This combination aids the drying of any aerosol injected into the sheath flow, which will be fully dried before reaching the UCASS at the 


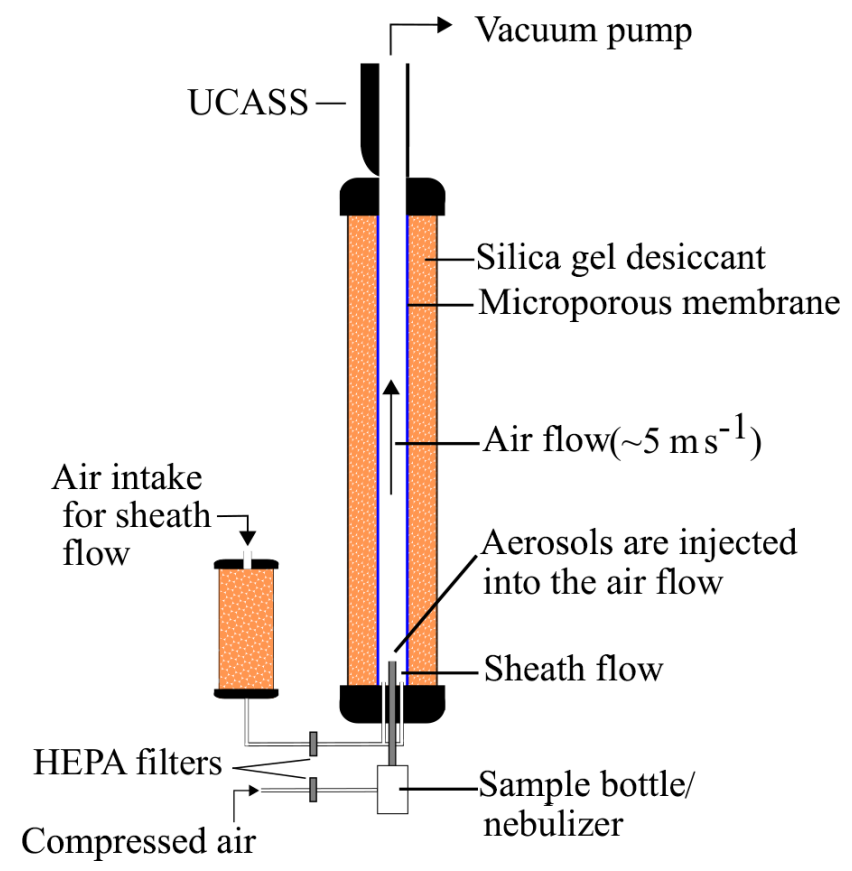

Figure 8. Experimental setup used to take calibration measurements. A vacuum pump is used to draw air through the drying column. The air intake is taken from ambient air that is first passed through desiccant and then a HEPA filter. This clean dry air is then directed through a concentric ring of pipes at the bottom of the drying column to create a clean, dry sheath flow. The aerosol is then injected into the sheath flow via the TSI tri-jet aerosol generator (for wet dispersion) or via a sample bottle for dry particles. The sheath flow constrains the aerosol in the centre of the air flow, which is carried directly through the sensing area of the UCASS.

top of the column. A vacuum pump is used in line with the UCASS to establish an air flow of $3-5 \mathrm{~m} \mathrm{~s}^{-1}$ (the intended operational velocity of the UCASS). Two different aerosol input techniques are used for wet and dry dispersion. The PSL microspheres are suspended in an aqueous solution and are aerosolized using a TSI Tri-Jet 3460, which is fed directly into the sheath flow. To disperse the dry calibration standards, a small amount of beads are placed into a small dispersion bottle consisting of an inlet and outlet tube. A burst of dried, filtered air in the inlet pipe creates a turbulent environment inside the bottle which aids the breakup of any agglomerates. The outlet pipe is then directed into the sheath flow and the dispersed particles are carried in the airflow through the UCASS.

As discussed above, to avoid sizing uncertainties associated with bin width during calibration, a calibration-specific firmware is utilized, which allows particle-by-particle $(\mathrm{PbP})$ pulse heights to be recorded. Measurements of various calibration standards are shown in Fig. 9. Figure 9a shows measurements from the high-gain version of the UCASS, which has a nominal sizing range of $0.4-17 \mu \mathrm{m}$, and Fig. 9b shows measurements from the "low-gain" version of the UCASS, which has a nominal sizing range of $1-40 \mu \mathrm{m}$. Calibrations are always conducted with the maximum number of particle standards available, and the data presented in Fig. 9 show all available standards at the time of publishing. The UCASS units used for the experiments presented in Sect. 3 were calibrated using five (or more) point calibrations using the particle standards available at the time. Although PSL and glass beads are typically considered monodisperse for calibration purposes, the full size range can be broad. Therefore, the full size distribution of the aerosol is measured, and the mean, median and modal value of the whole distribution are found. Manufacturers may describe the average size of their test particles using different averages, and therefore it is necessary to select the correct average for each sample type. For these calibrations, the mean values are used for PSL and soda-lime glass, whereas the median is used for borosilicate glass. In cases where the full distribution is not captured, the modal value is used. This occurs in the case that the full size range of a particular sample may extend beyond the measurable limits of the instrument. For example, in Fig. 9, the largest diameter aerosol used in this calibration is $14.4 \mu \mathrm{m}$, and it can be seen that the distribution is cut off at the point where the detector saturates. The same occurs for the low-gain version for the $37.36 \mu \mathrm{m}$ sample. In these cases, the full distribution could not be measured, and therefore the mean or median cannot be used, thus the modal value is used instead.

Theoretically, the instrument response is directly proportional to the scattering cross section. However, the instrument response may differ from the theoretical response due to manufacturer tolerances in the optical and electronic components. Some variations, such as laser power and amplifier gain, will cause constant offsets over the measurement range. However, some offsets may be non-linear due to the varying signal-to-noise ratio (SNR) across the measurement range and non-linearity in the detector sensitivity. To account for all offsets, the log of instrument response (analog-to-digital counts, AD) is plotted against the log of the scattering cross section and a line of best fit is applied, as shown in Fig. 10.

A linear fit is applied to link the scattering cross section to the instrument response. For the examples shown, the relationship for the high-gain UCASS is given by

$\ln (\mathrm{AD})=0.87 \ln \left(\sigma_{\mathrm{sca}}\right)+4.8$,

and the relationship for the low-gain UCASS is given by

$\ln (\mathrm{AD})=0.78 \ln \left(\sigma_{\mathrm{sca}}\right)+3.7$.

These equations can then be applied to any particulate (e.g. mineral dust, water) by computing the scattering cross sections for discretized diameters across the measurement range and relating the instrument response to the particle diameter. Using this technique, finalized calibration curves are produced for five materials: PSL, soda-lime glass, borosilicate glass, water and mineral dust, as shown in Fig. 11. If a priori information of the aerosol type is known, then the 
(a)
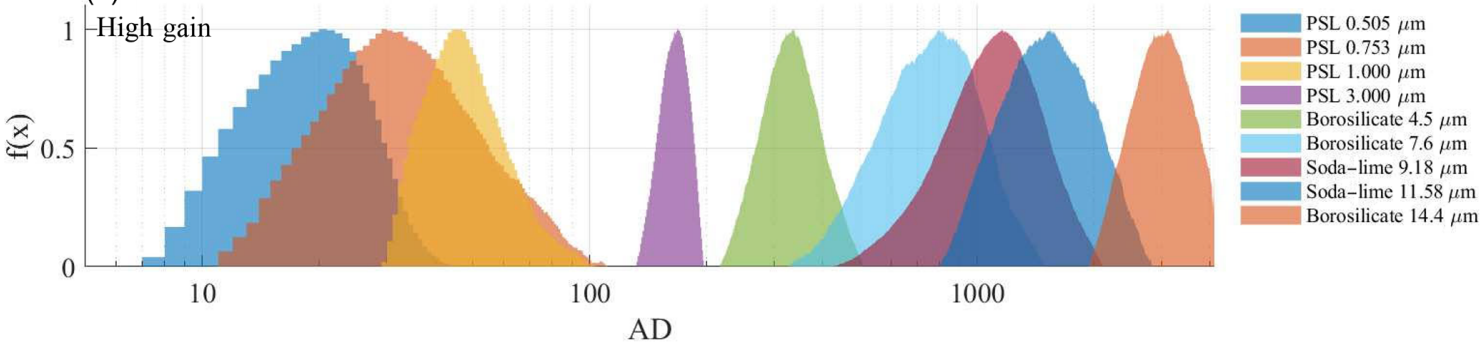

(b)

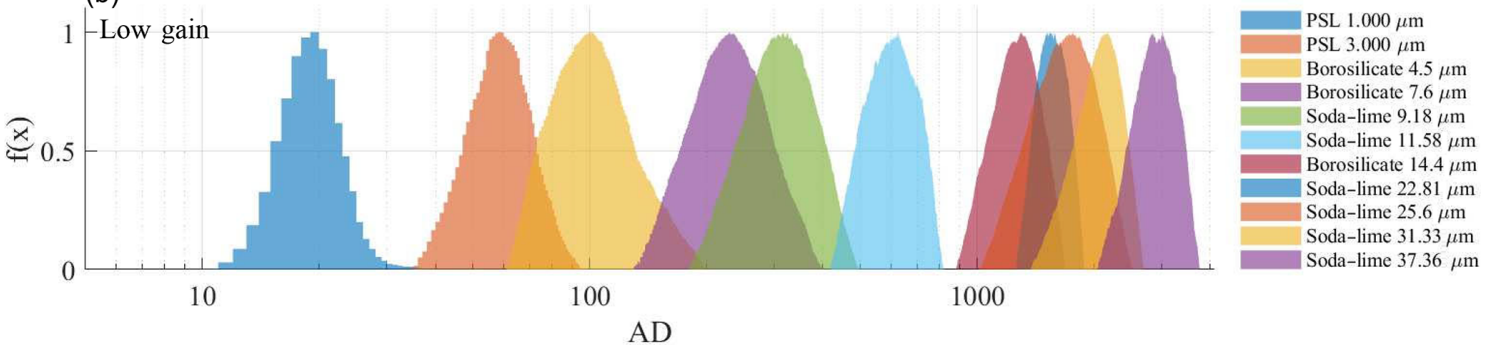

Figure 9. Measured instrument responses for various NIST-traceable calibration standards, including PSL, borosilicate glass and sodalime glass. $f(x)$ is the normalized counts, as measured by the instrument; for presentation purposes, each distribution is normalized to a peak height of 1. Panel (a) shows measurements conducted using a "high-gain" version of the UCASS, and panel (b) shows measurements conducted using a "low-gain" version.

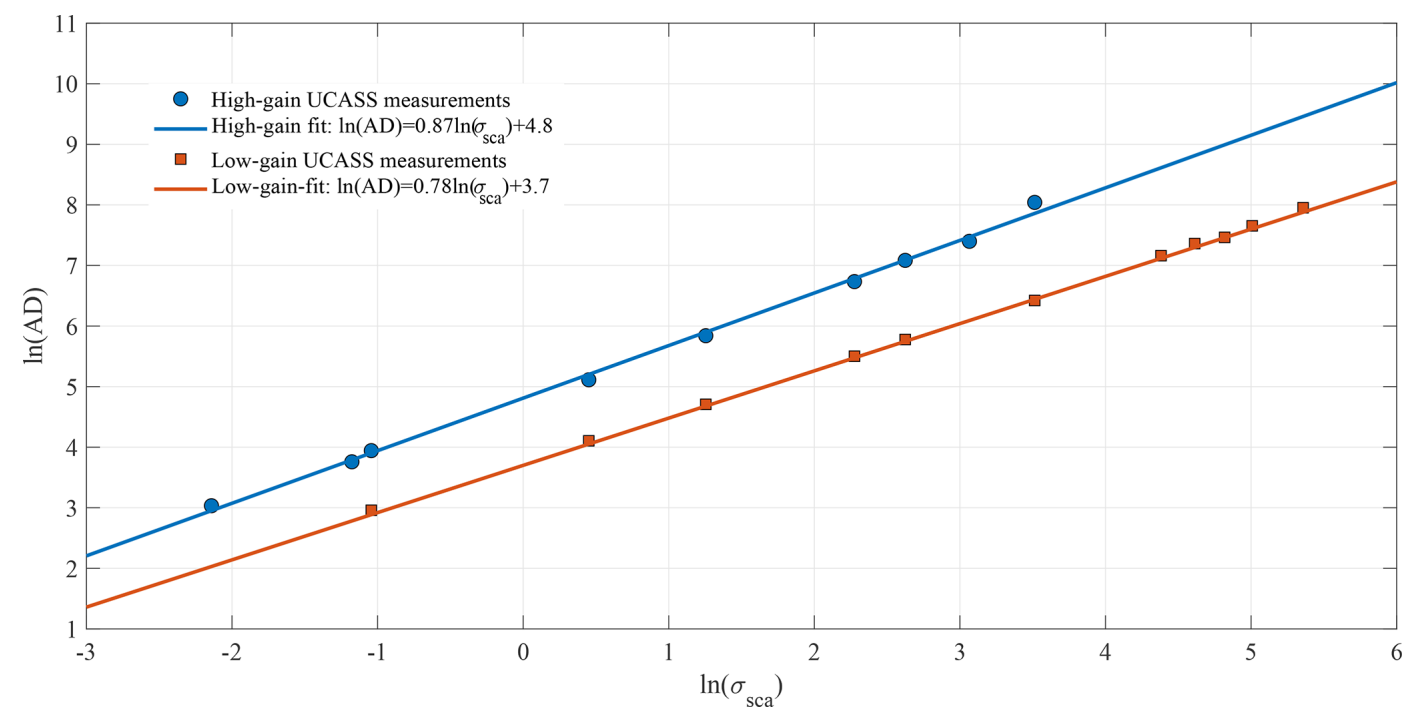

Figure 10. The log of the measured instrument response (AD) is plotted against the log of the scattering cross section ( $\left.\sigma_{\text {sca }}\right)$ for the calibration standards used. For PSL and Duke Scientific borosilicate glass beads, the mean instrument response is used, as this is how the manufacturer specifies the particle size. For the Whitehouse Scientific soda-lime glass beads, the sample size is defined by the median, and thus the median instrument response is plotted.

calibration curve can be chosen to best suit the application. The calibration curve can then be used to select the boundaries of up to 16 size bins (this is limited to 10 if interfacing the UCASS via XDATA protocol). Since the relationship between $\ln (\mathrm{AD})$ and $\ln \left(\sigma_{\text {sca }}\right)$ remains valid for any material and shape of aerosol. If post factum information on the particle shape or refractive index becomes available (i.e. via analysis of co-located measurements), then a post calibration can be applied.

\subsection{Evaluation of air flow uncertainty}

The UCASS is a naturally aspirated system, by which an external air flow (relative to the UCASS) is required to transport particles through the sensing area. The main advantage 

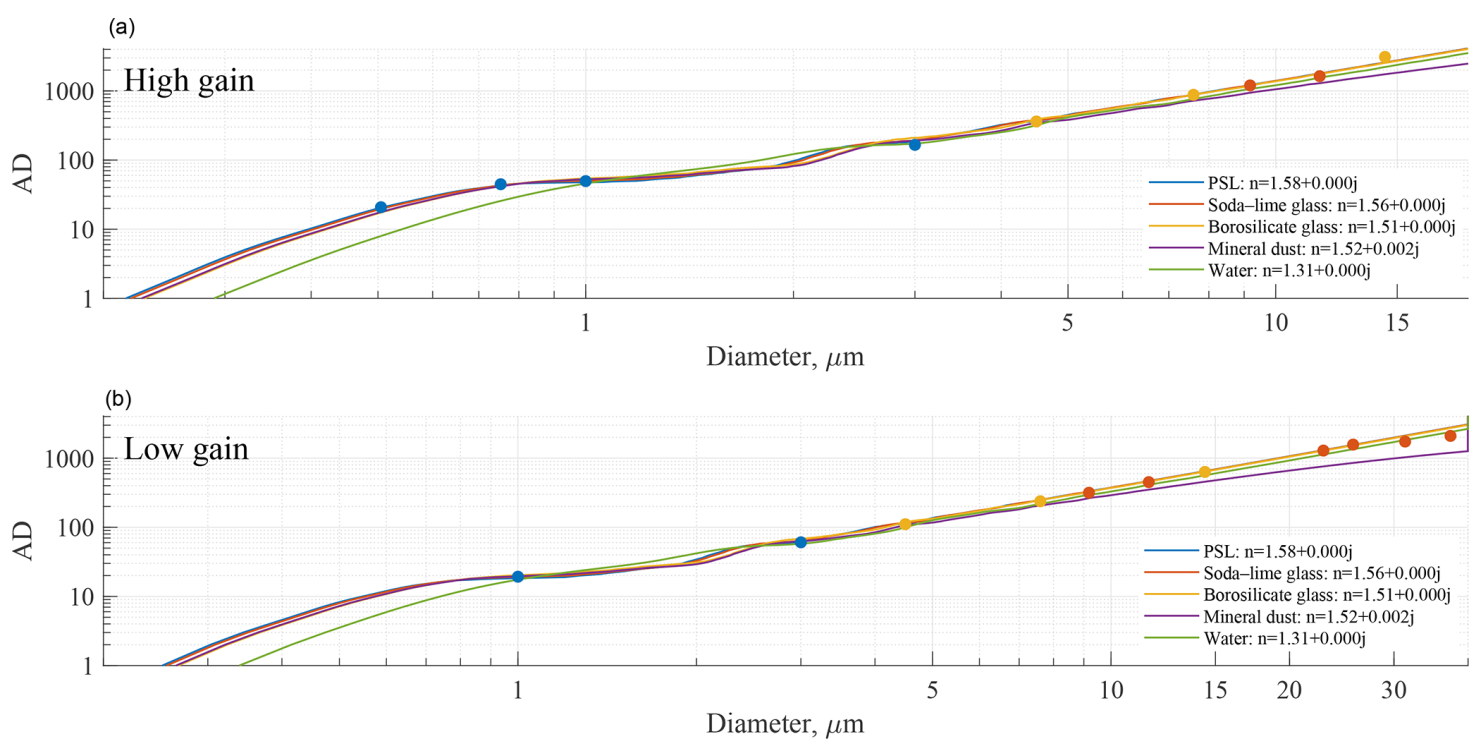

Figure 11. Final calibration curves for a high-gain (a) and low-gain (b) UCASS. The geometric diameter is plotted against instrument response for varying materials. The measured values (as shown in Fig. 9) are overlaid on the calibration curves and shown as filled circles, where the colour denotes the material. If a priori information of the refractive index is known, the calibration curve can be selected to best suit the material being measured. If post factum information about the material becomes available, the calibration can be adjusted.

of this setup is the reduction of particle loss mechanisms induced by complex aerodynamic systems and non-isokinetic sampling, which has been evaluated empirically for artificially aspirated systems (Spiegel et al., 2012; Hangal and Willeke, 1990; Von Der Weiden et al., 2009). However, the sampling efficiency is still dependent on the axial characteristics of the external airflow, hence a range of accepted (aerodynamic) operating conditions must be defined. To understand the airflow through the sample area, computational fluid dynamics (CFD) using the "Star CCM+" commercial code are used to model the air flow through the instrument at varying angles of attack. The CFD simulation is a twodimensional model on the symmetry plane of the UCASS, this was chosen because the velocity of an "air parcel" in a subsequent plane to this is likely to be similar, meaning the viscous stress between planes is negligible. The fundamental equations behind this CFD are the Reynolds-averaged Navier-Stokes (RANS) equations, which were chosen for computational efficiency when compared to direct numerical simulation.

Figure 12 shows the air flow through the UCASS for an external velocity of $5 \mathrm{~m} \mathrm{~s}^{-1}$. For an axial air flow, the air velocity through the sample area is $5.6 \mathrm{~m} \mathrm{~s}^{-1}, 12 \%$ higher than the external air flow. Whilst the drag on the inside walls of the UCASS causes the airflow to slow down, the sample area lies outside this boundary layer and is therefore subject to a slightly higher air speed. The UCASS inlet is asymmetric due to the design constraints making it compatible with the KITsonde dropsonde system, and therefore we must also consider the effect of tilt in different directions. As the UCASS is tilted upwards, the air flow through the sample area in- creases; however, as it is tilted downwards, the air speed decreases. This relationship between tilt and air speed is asymmetric, with negative angles of attack having a greater impact on the air flow. Therefore, to retrieve reliable concentration measurements from the UCASS, the airflow or angle of attack must be known.

When the UCASS is launched on a meteorological balloon, the balloon-payload configuration acts as a pendulum system. To constrict the movement of the UCASS, the payload is configured as a double pendulum, whereby the UCASS is secured by a line below the balloon and the meteorological sonde is secured below the UCASS. This double pendulum configuration allows fast energy dissipation while at the same time ensuring small amplitude of the UCASS oscillations, generally smaller than the amplitude of the lowest element, the radiosonde. Although the UCASS still oscillates, model results show that the tilt is constrained to within $\pm 5^{\circ}$ as shown in Fig. 13 .

By constraining the tilt of the UCASS within these limits, model results show that the mean air speed through the sample area is equal to $5.4 \mathrm{~m} \mathrm{~s}^{-1}$, with a standard deviation of $0.3 \mathrm{~m} \mathrm{~s}^{-1}$, which is used to compute the number concentrations. For dropsonde systems, a similar configuration is used, whereby the sonde is tethered between the parachute and the meteorological sonde and the angle of tilt is constrained to within the same boundaries. 

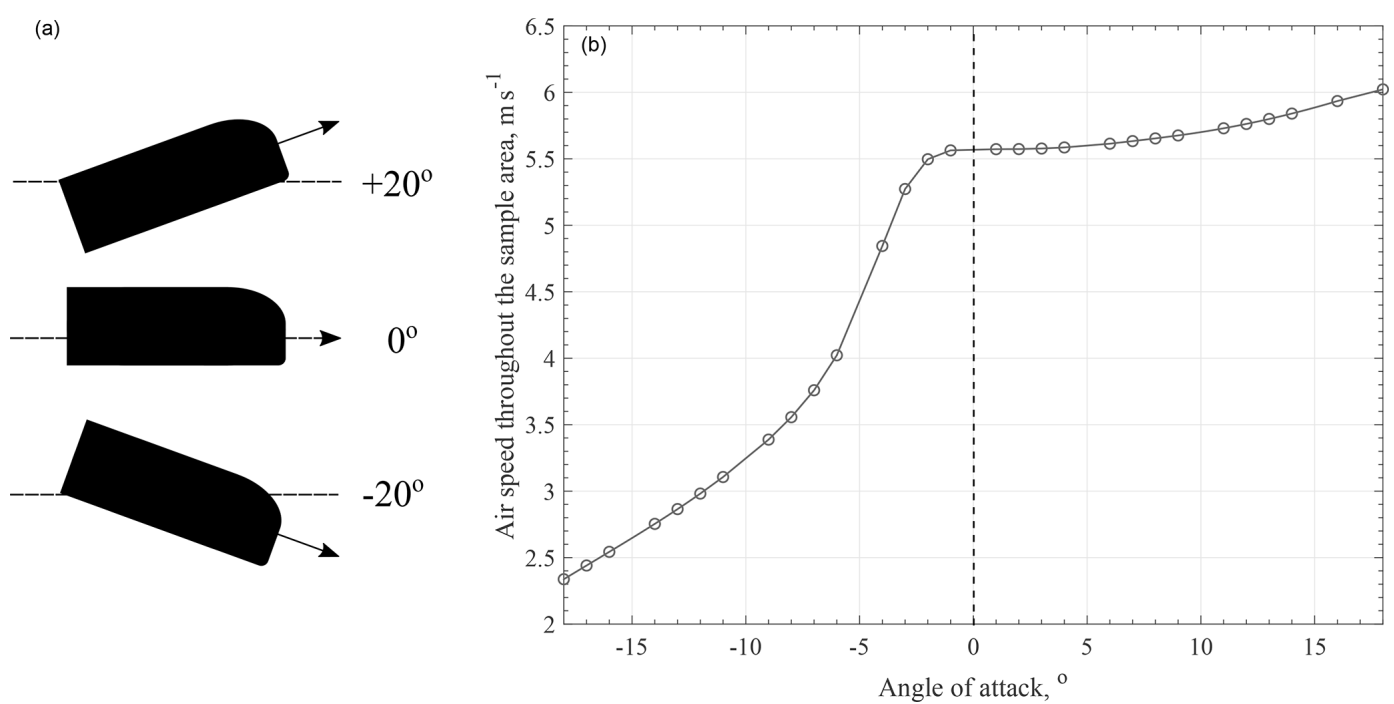

Figure 12. Model results showing the air velocity in the sensing area. Panel (a) shows how the tilt direction is described in relation to the instrument geometry. Panel (b) shows the simulated flow velocity in the sample for tilt angles between -20 and $20^{\circ}$ in an external air flow of $5 \mathrm{~m} \mathrm{~s}^{-1}$.

\section{Results}

\subsection{Laboratory inter-comparisons}

Inter-comparison tests were conducted in laboratory settings to assess the sizing and counting ability of the UCASS in comparison to reference instrumentation.

\subsubsection{Sizing comparisons}

To assess the sizing ability of the UCASS, a TSI 3300 optical particle sizer (OPS) is used to measure the same particle calibration standards as discussed in Sect. 2.4.2. The TSI OPS is an optical particle counter, capable of sizing and counting particles in the $0.3-10 \mu \mathrm{m}$ range in 16 user-configurable size bins. For comparative purposes, the TSI was set to the finest size resolution for each measurement, focusing only on the size range of interest. The results are compared to the measurements taken by the UCASS while in particle-by-particle mode (as discussed in Sect. 2.4.2). Measurements are also compared with statistical values given by the manufacturer of the particle standard, where available. These measurements are shown in Fig. 14.

\subsubsection{Counting comparisons}

To assess the counting ability of the UCASS, an aerosol chamber was filled with polydisperse aerosol. The polydisperse aerosol was generated using a vaporizer containing a mixture of propylene-glycol and vegetable glycerine. The TSI was mounted in the chamber and sampled continuously, the UCASS was mounted nearby the TSI and a pump attachment was used to draw air through the inlet. Measurements were repeated using different size bins in order to col- lect data across the full measurable range $(0.4-10 \mu \mathrm{m})$ and with a higher resolution at smaller sizes. Typical concentrations during the experiment were of the order of $10^{3} \mathrm{~cm}^{-2}$. The measured concentrations of the UCASS are compared to the measured concentrations of the TSI in Fig. 15, where the data are averaged over all experiments and the error bars represent standard deviations. A dotted line represents the $1: 1$ ratio (i.e. UCASS concentration is equal to TSI concentration). It can be seen that the ratio of measured concentrations varies between 0.8 and 1.2 across all size ranges, and therefore the two instruments agree to within $20 \%$. For 19 out of 20 measured size ranges, the $1: 1$ ratio lies within the standard deviation of the data.

\subsection{In situ intercomparisons}

A low-gain configuration of the UCASS (calibrated for water droplets) was tested at the Observatoire de Physique du Globe de Clermont-Ferrand (OPGC) observatory, located atop the Puy De Dôme volcano at an altitude of $1465 \mathrm{~m}$. The observatory consists of a rooftop measurement platform with an integrated wind tunnel capable of pumping through the passing clouds. As the UCASS requires an external air flow, the UCASS was tested in the wind tunnel, co-located with a cloud droplet probe (CDP-2) from Droplet Measurement Technologies (DMT) (Lance et al., 2010). The CDP-2 is an open-geometry system that provides size and concentration measurements in the range $2-50 \mu \mathrm{m}$ and is intended for air speeds of $10-250 \mathrm{~m} \mathrm{~s}^{-1}$. During a stratocumulus event, the UCASS and CDP were co-located in the wind tunnel and the cloud was drawn through at varying speeds from $5 \mathrm{~m} \mathrm{~s}^{-1}$ (the lowest operational velocity of the wind tunnel) to $20 \mathrm{~m} \mathrm{~s}^{-1}$. Figure 16 shows the measured liquid water content (LWC) 


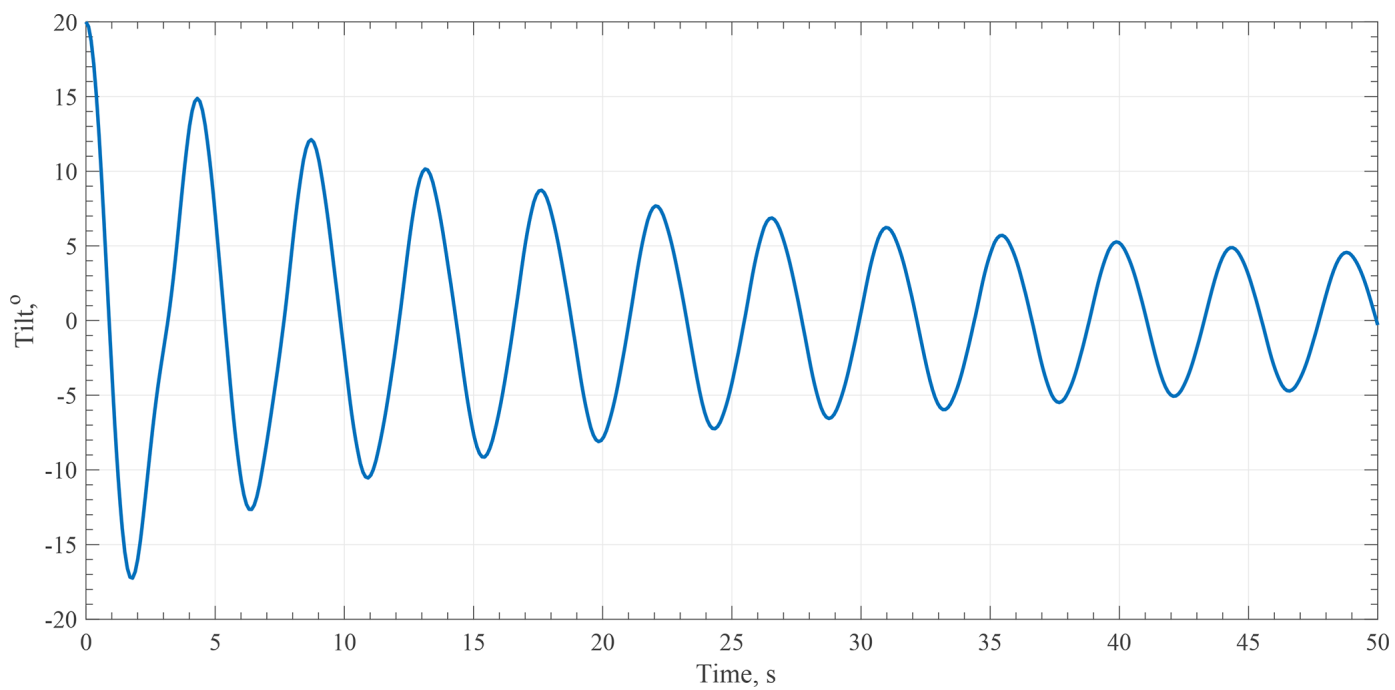

Figure 13. Model results showing the angular tilt of the UCASS with respect to the direction of ascent. Initial oscillations can reach $\pm 20^{\circ}$, although these are damped after $\approx 30 \mathrm{~s}$ and constrained within $\pm 5^{\circ}$.
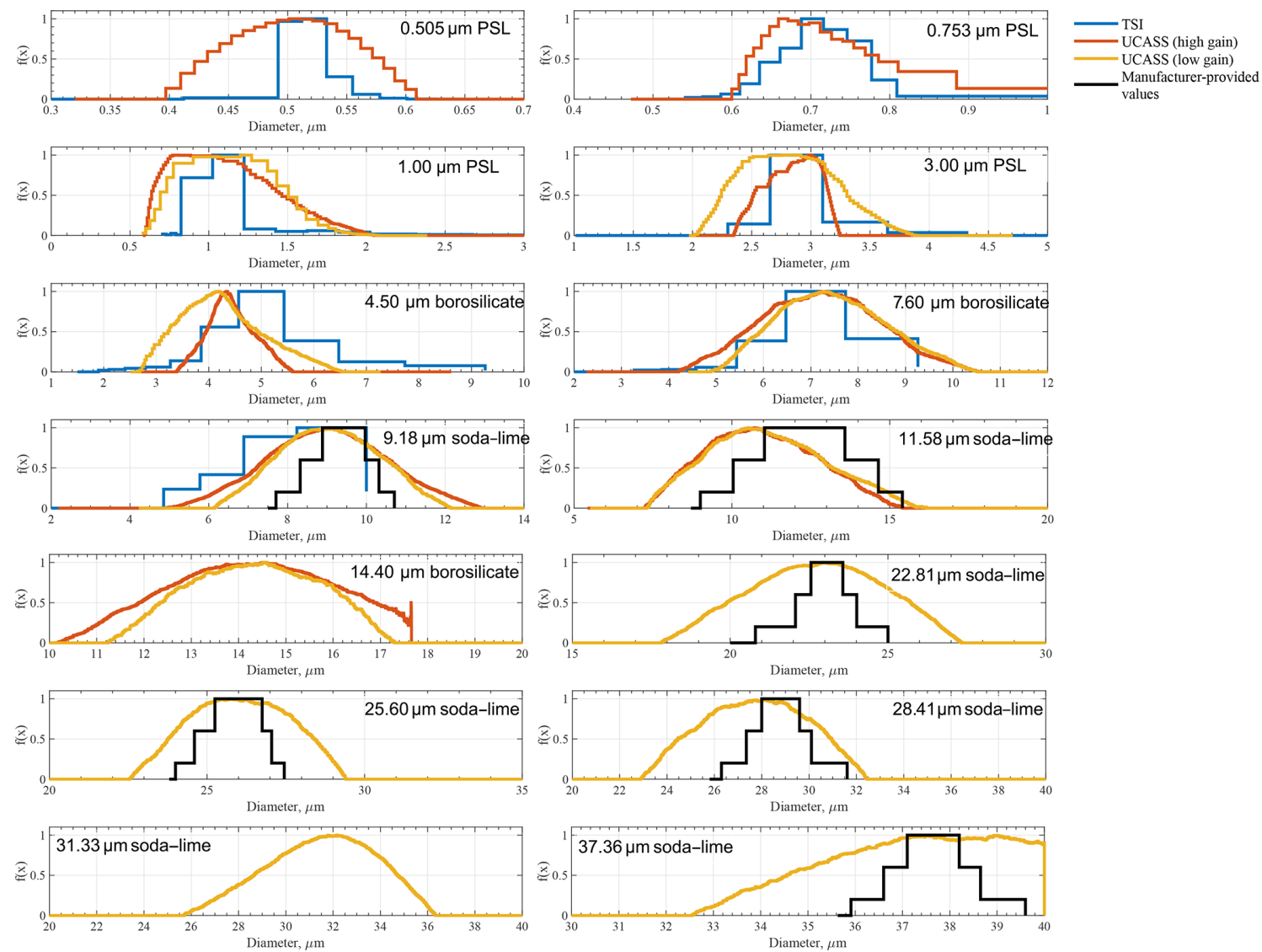

Figure 14. Measurements of particle size distribution from the TSI 3330 OPS, the high-gain UCASS and the low-gain UCASS. Manufacturer values are also shown, where available. Data for PSL and borosilicate standards are summarized in Table 1, while data for soda-lime samples are summarized in Table 2. 
Table 1. Numerical summary of data shown in Fig. 14 pertaining to PSL and borosilicate particle standards. The first column shows the mean and standard deviation of calibration standards as given by the manufacturer. The remaining columns show distributions measured by the TSI OPC, the high-gain UCASS and low-gain UCASS. Incomplete distributions (i.e. where the full size distribution exceeds beyond the measurable size range) are denoted with an asterisk.

\begin{tabular}{llrrr}
\hline Manufacturer values (mean and SD), $\mu \mathrm{m}$ & Material & TSI & UCASS (high gain) & UCASS (low gain) \\
\hline $0.505 \pm 0.016$ & PSL & $0.507 \pm 0.02$ & $0.500 \pm 0.05$ & - \\
$0.753 \pm 0.01$ & PSL & $0.697 \pm 0.07$ & $0.696 \pm 0.07$ & - \\
$1 \pm 0.01$ & PSL & $1.029 \pm 0.34$ & $1.114 \pm 0.35$ & $1.117 \pm 0.4$ \\
$3 \pm 0.07$ & PSL & $2.700 \pm 0.25$ & $2.903 \pm 0.22$ & $2.823 \pm 0.44$ \\
$4.5 \pm 0.4$ & borosilicate & $4.560 \pm 1.13$ & $4.419 \pm 0.39$ & $4.373 \pm 0.74$ \\
$7.6 \pm 0.4$ & borosilicate & $6.493 \pm 1.05^{*}$ & $7.35 \pm 1.20$ & $7.53 \pm 1.12$ \\
$14.4 \pm 0.8$ & borosilicate & - & $14.418 \pm 1.66$ & $14.394 \pm 1.31$ \\
\hline
\end{tabular}

Table 2. Numerical summary of data shown in Fig. 14 pertaining to soda-lime glass particle standards. The first column shows the median and interquartile range (iqr) of calibration standards as given by the manufacturer. The remaining columns show distributions measured by the TSI OPC, the high-gain UCASS and low-gain UCASS. Incomplete distributions (i.e. where the full size distribution exceeds beyond the measurable size range) are denoted with an asterisk.

\begin{tabular}{lrrr}
\hline Manufacturer values (median and IQR) & TSI & UCASS (high gain) & UCASS (low gain) \\
\hline $9.18(\mathrm{iqr}=1.2)$ & $6.889(\mathrm{iqr}=1.4)^{*}$ & $9.17(\mathrm{iqr}=2.14)$ & $9.14(\mathrm{iqr}=1.8)$ \\
$11.58(\mathrm{iqr}=2.4)$ & - & $11.07(\mathrm{iqr}=2.5)$ & $11.18(\mathrm{iqr}=2.7)$ \\
$22.81(\mathrm{iqr}=1.1)$ & - & - & $22.88(\mathrm{iqr}=3.0)$ \\
$25.60(\mathrm{iqr}=1.4)$ & - & - & $26.09(\mathrm{iqr}=2.4)$ \\
$28.41(\mathrm{iqr}=1.7)$ & - & - & $27.86(\mathrm{iqr}=3.2)$ \\
31.33 & - & - & $31.72(\mathrm{iqr}=3.2)$ \\
$37.36(\mathrm{iqr}=1.1)$ & - & - & $38.38(\mathrm{iqr}=3.5)^{*}$ \\
\hline
\end{tabular}

taken by the UCASS (blue) and the CDP (orange). Both instruments measured at a rate of $1 \mathrm{~Hz}$ (shown by dotted lines), and the solid lines represent the smoothed data, using a 10point moving average. The air speed is shown via a dotted green line corresponding to the right-hand $y$ axis. It can be seen that throughout the experiment both the UCASS and CDP capture the same temporal variations in the liquid water content, although the magnitudes start to diverge at air velocities above $17 \mathrm{~m} \mathrm{~s}^{-1}$. This under-counting by the UCASS is expected due to the short ToF (discussed in Sect. 2.3), which causes the particles to be rejected. This ToF threshold is intended to prevent miscounting of short pulses, which can be caused by electrical noise. However, the ToF limits can be altered to suit the measurement platform. In the overlapping measurement range (air speeds between 10 and $15 \mathrm{~m} \mathrm{~s}^{-1}$ ), the ratio of UCASS-measured LWC to CDP-measured LWC is equal to 1.02 .

\subsubsection{Dropsonde system}

Dropsondes were launched from the Dornier 128 aircraft north of Magdeburg, Germany, on 3 August 2013. The packages contained the UCASS in tandem with KITsondes (Wieser et al., 2014), for co-located particle and meteorological data. The size distribution profiles measured by the UCASS indicated mineral dust present in the free troposphere during 3 August for a drop conducted at 13:10 UTC. At 15:34 UTC, AERONET sun photometry retrievals (Dubovik and King, 2000) from IfT Leipzig (located $100 \mathrm{~km}$ south-south-east of Magdeburg) confirmed the presence of dust. The integrated size distribution measured by the UCASS is compared to the AERONET inversion from Leipzig in Fig. 17a. The size distribution is integrated for the column between 3 and $5 \mathrm{~km}$ to exclude boundary layer aerosol over the Colbitz-Letzlinger Heide area (the EDR74 exclusion zone). Figure 17b shows the dust dispersion model for 12:00 UTC using the MACC (Monitoring Atmospheric Composition and Climate) forecast, showing the transport of dust over Germany from the Sahara. The locations of Magdeburg and Leipzig are marked by red and yellow crosses, respectively.

In a further drop during this dust event, a UCASS dropsonde system was deployed $3 \mathrm{~min}$ later at 13:13 UTC. This payload measured a thin, embedded cloud layer as shown by high number concentrations at larger sizes at $4 \mathrm{~km}$. This is illustrated in Fig. 18a, where the number concentrations for each of the 16 size bins are shown. Over the $6 \mathrm{~km}$ profile, the majority of particulates counted measured less than $3 \mu \mathrm{m}$ in diameter, except for a thin layer at $4 \mathrm{~km}$ with high concentrations of particles in larger size bins. This change in concentration and size suggested the presence of a thin cloud layer, 


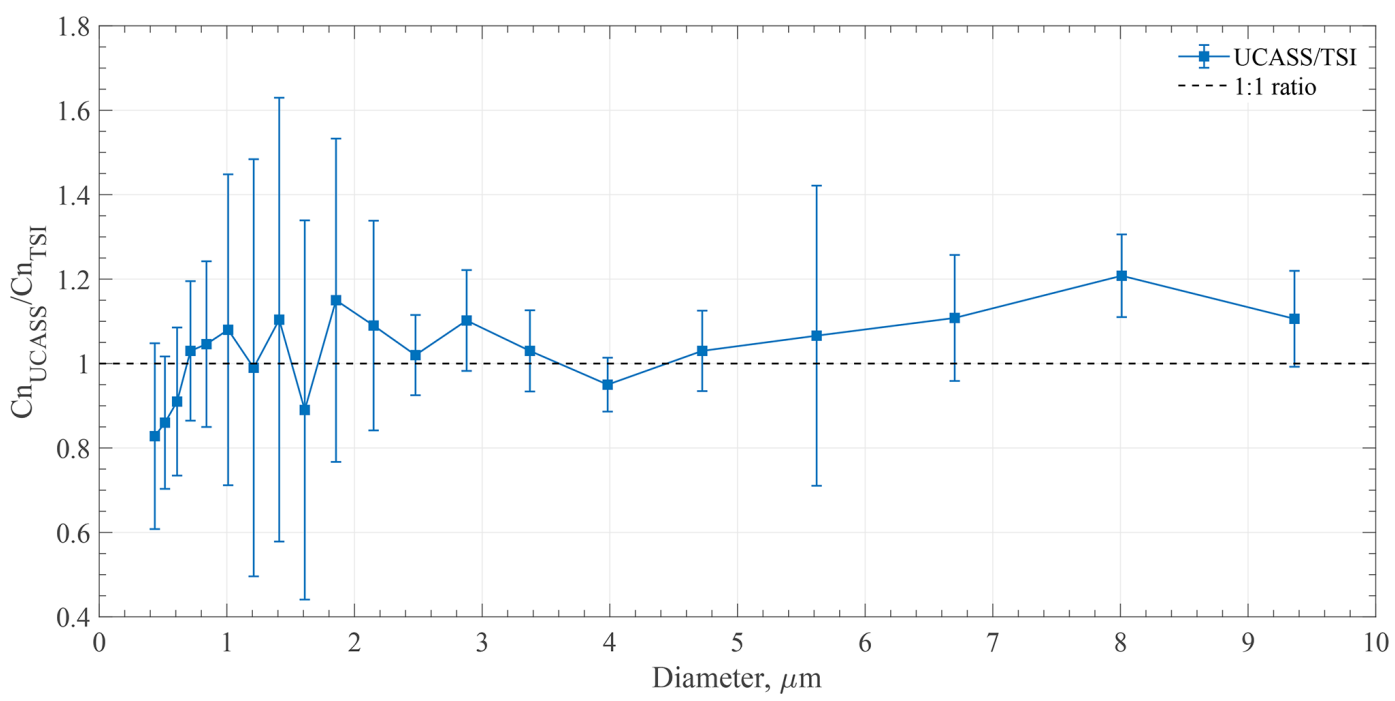

Figure 15. Ratio of UCASS-measured number concentrations (Cn ${ }^{\text {UCASS }}$ ) to TSI-measured number concentrations $\left(\mathrm{Cn}^{\mathrm{TSI}}\right)$, where data points represent means averaged over 100 readings and error bars represent standard deviations. The $1: 1$ ratio is shown as a dashed black line.

which was confirmed by the humidity profile measured by the attached KITsonde shown in Fig. 18b, which measured high humidities at $4 \mathrm{~km}$. Figure $18 \mathrm{c}$ shows the effective diameter with respect to altitude, it can be seen that the Saharan dust layers above or below the cloud have an effective diameter of $\approx 2 \mu \mathrm{m}$. At $4 \mathrm{~km}$ when the UCASS enters the cloud layer, this effective diameter steeply increases to $\approx 6 \mu \mathrm{m}$. As discussed in Sect. 1, dust can cause the formation of clouds by acting as a cloud condensation nuclei, thus embedded clouds during dust events are not uncommon. However, the presence of cloud presents difficulties for remote sensing instrumentation, and therefore retrievals are not possible for cloud-contaminated datasets. So long as the UCASS is launched in tandem with a meteorological sonde, the measured humidity profiles can be used to differentiate between cloudy and non-cloudy conditions, and therefore the UCASS can be used to measure both cloud and aerosol size distributions even when both are present.

\subsubsection{Upsonde system}

The UCASS was used during the AERosol properties - Dust (AER-D) and Sunphotometer Airborne Validation EXperiment - Dust (SAVEX-D) campaigns over Cabo Verde during August 2015 (Marenco et al., 2018). A UCASS was launched as part of a balloon-based system in tandem with a GRAW DFM-09 during a Saharan dust event on 25 August, from Instituto Nacional De Meteorologia e Geofisica (INMG), Espargos, Sal island. The launch was conducted at 17:01 UTC from ground level $(70 \mathrm{~m}$ above sea level), this launch was timed to coincide with a deep profile (profile 6) conducted by SAVEX-D flight no. B934. The research aircraft started the profile from an altitude of $4 \mathrm{~km}$ at 17:10 UTC off the west coast of Boa Vista island $\left(\approx 0.75^{\circ} \mathrm{S}, 0.15^{\circ} \mathrm{W}\right.$ of the balloon launch site). The aircraft then flew due north, passing Sal island until reaching an altitude of $690 \mathrm{~m}$. Figure 19a shows the flight paths of the aircraft and balloon (up to $4 \mathrm{~km}$ ), whilst Fig. 19b shows the altitude of both profiles with respect to time. Figure 19c shows the near-real-time dust forecast from the Met Office Global Atmosphere model (Martin et al., 2018) for 18:00 UTC, where it can be seen that dust is advected westwards from the Sahara. The circular section shows a zoomed-in image over the Cabo Verde islands, and the islands of Sal and Boa Vista are highlighted by a red rectangle. It can be seen from the forecast that the aircraft and balloon profiles were conducted at the leading edge of a dust layer, and therefore, even though the spatial and temporal differences between the two profiles are minimal, some variability in the dust layer may be expected.

Figure 20a shows the mass concentration profile measured by the UCASS, compared with measurements from the aircraft-mounted PCASP (Passive Cavity Aerosol Spectrometer Probe). The PCASP is an aircraft-mounted OPC by Droplet Measurement Technologies. Similarly to the UCASS, the PCASP utilizes wide-angle scattered light, with the primary reflector covering the angular range $35-120^{\circ}$. For comparative purposes, the mass concentrations shown only apply to the overlapping measurable size range of the UCASS and PCASP, in this case the size range is from 0.4 to $3 \mu \mathrm{m}$, corresponding to the first seven bins of the UCASS. Figure 20b shows the ratio of the mass concentrations measured by the UCASS and PCASP, respectively. Over the $4 \mathrm{~km}$ profile, the average ratio is 1.2 , with the greatest differences between the two measurements occurring at the base and top of the dust layer $(\approx 1.6$ and $4 \mathrm{~km}$, respectively). The dust layer was advected from the east, as shown in Fig. 19, thus 


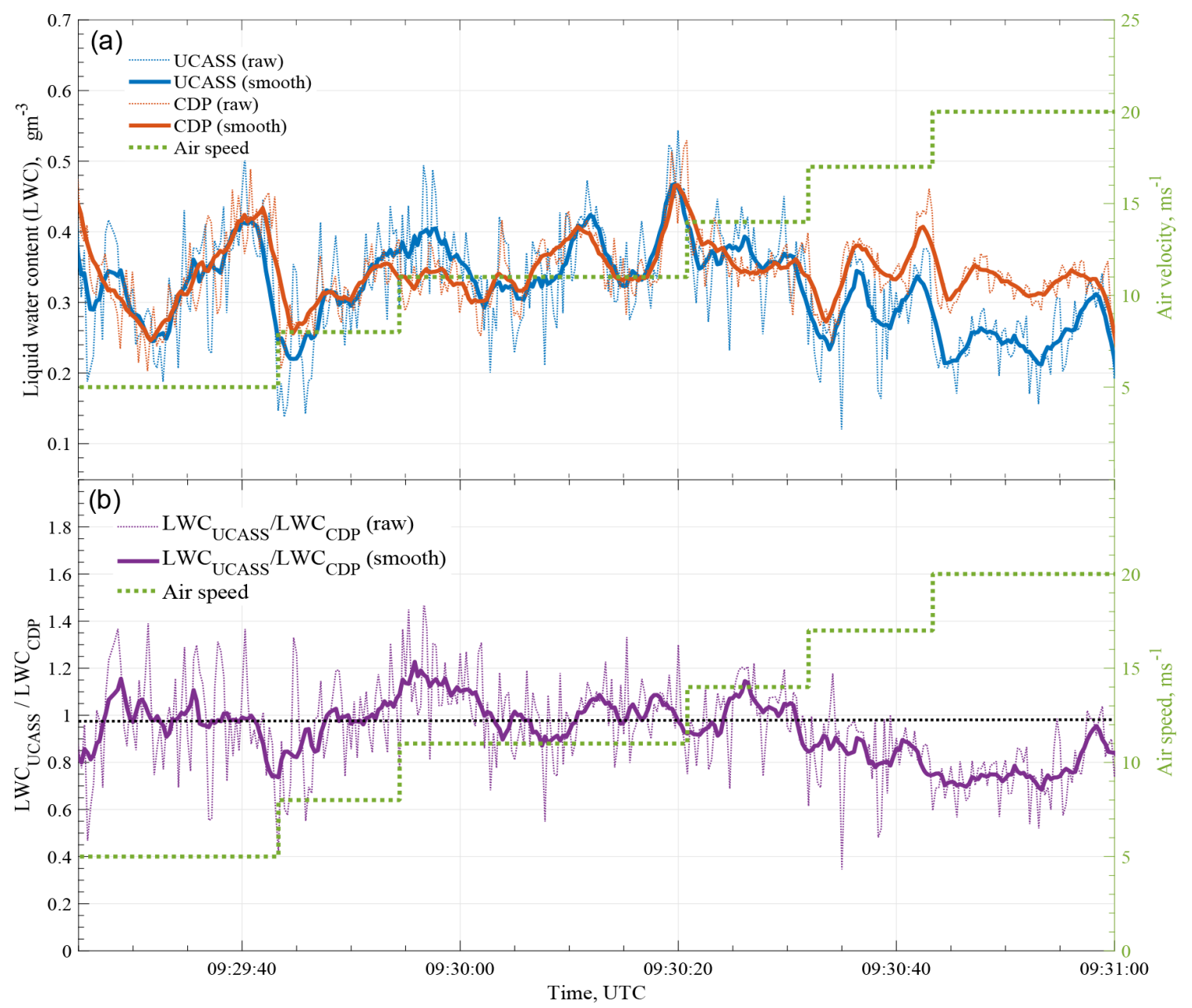

Figure 16. (a) Measured liquid water content (LWC) by co-located UCASS and CDP instruments at varying air speeds. The two instruments were installed side-by-side in the wind tunnel at Puy de Dôme during a stratocumulus event, and the air speed was increased from 5 to $20 \mathrm{~m} \mathrm{~s}^{-1}$. (b) Ratio of the LWC measured by the UCASS to the LWC measured by the CDP. The dotted black line shows the $1: 1$ ratio.

the spatial separation between the two profiles explains the discrepancies. The more easterly UCASS measurement captures higher concentrations and a higher layer height, whilst the more westerly PCASP measurement measures a lower layer height, likely due to gravitational settling.

\section{Conclusions}

The Universal Cloud and Aerosol Sounding System (UCASS) is a lightweight, open-path optical particle counter (OPC), designed for the measurement of micron-scale particles. The open-geometry design bypasses issues associated with narrow inlets, such as clogging and counting uncertainties associated with complex air flow systems. Furthermore, by removing the need for heavy or expensive pumps, the size, weight and cost of the instrument are kept to a minimum. The UCASS is $180 \mathrm{~mm}$ long, $64 \mathrm{~mm}$ in diameter and $280 \mathrm{~g}$ in weight. The UCASS can then be used as a stand-alone instru- ment whereby data are logged autonomously via an on-board SD card, or the UCASS can be interfaced via XDATA protocol with several commercially available meteorological sondes. Therefore, the UCASS is suitable to create low-weight payloads for dropsonde systems, balloon-borne systems or unmanned aerial vehicles (UAVs).

The UCASS can be configured as a high-gain or lowgain mode, giving nominal measurable ranges of $\approx 0.4-17$ and $\approx 1-40 \mu \mathrm{m}$, respectively, with up to 16 configurable size bins. As the UCASS measures predominantly side-scattered light, the sizing ability is not hindered by the presence of Mie oscillations that can cause uncertainties with forwardscattering probes. However, as side-scattered light is more dependent upon the refractive index of the scattering particle, the exact detection limits are dependent upon the refractive index of the material being measured. To ensure accurate sizing, an eight or more point calibration is applied using a variety of particle standards, including PSL, soda-lime glass and borosilicate glass. To account for differences in re- 
(a)

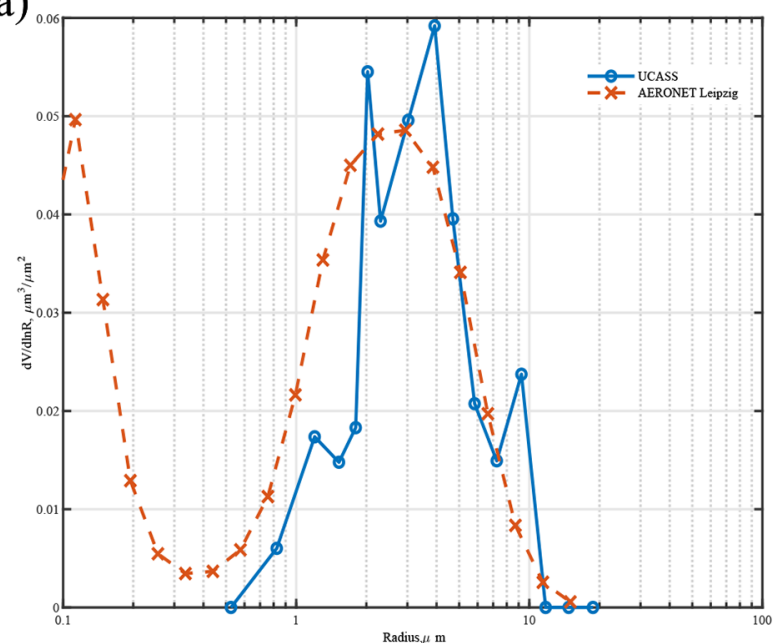

(b)

03/08/2013 00:00 UTC MACC forecast t+012 VT:

Dust aerosols optical depth at $550 \mathrm{~nm}$

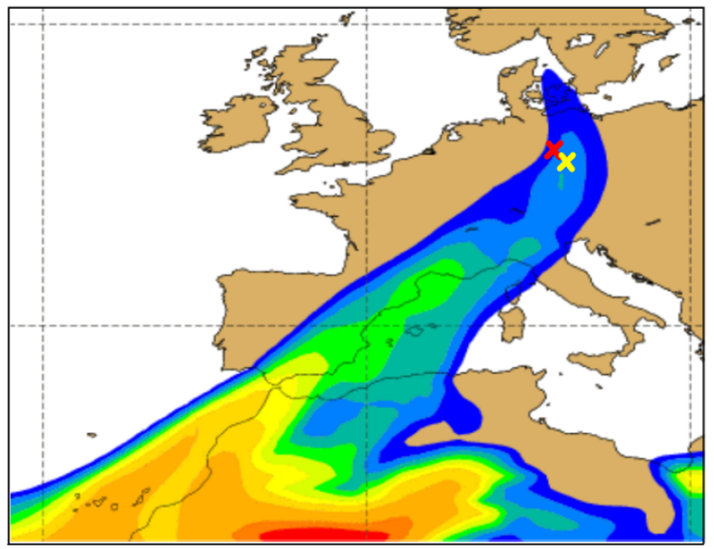

Figure 17. (a) Integrated aerosol size distribution measured by the UCASS compared with the AERONET inversion (as retrieved from the sun photometer data) from Leipzig. (b) Dust dispersion model showing Saharan dust transport over Leipzig (marked by a yellow cross) and Magdeburg (marked by a red cross).
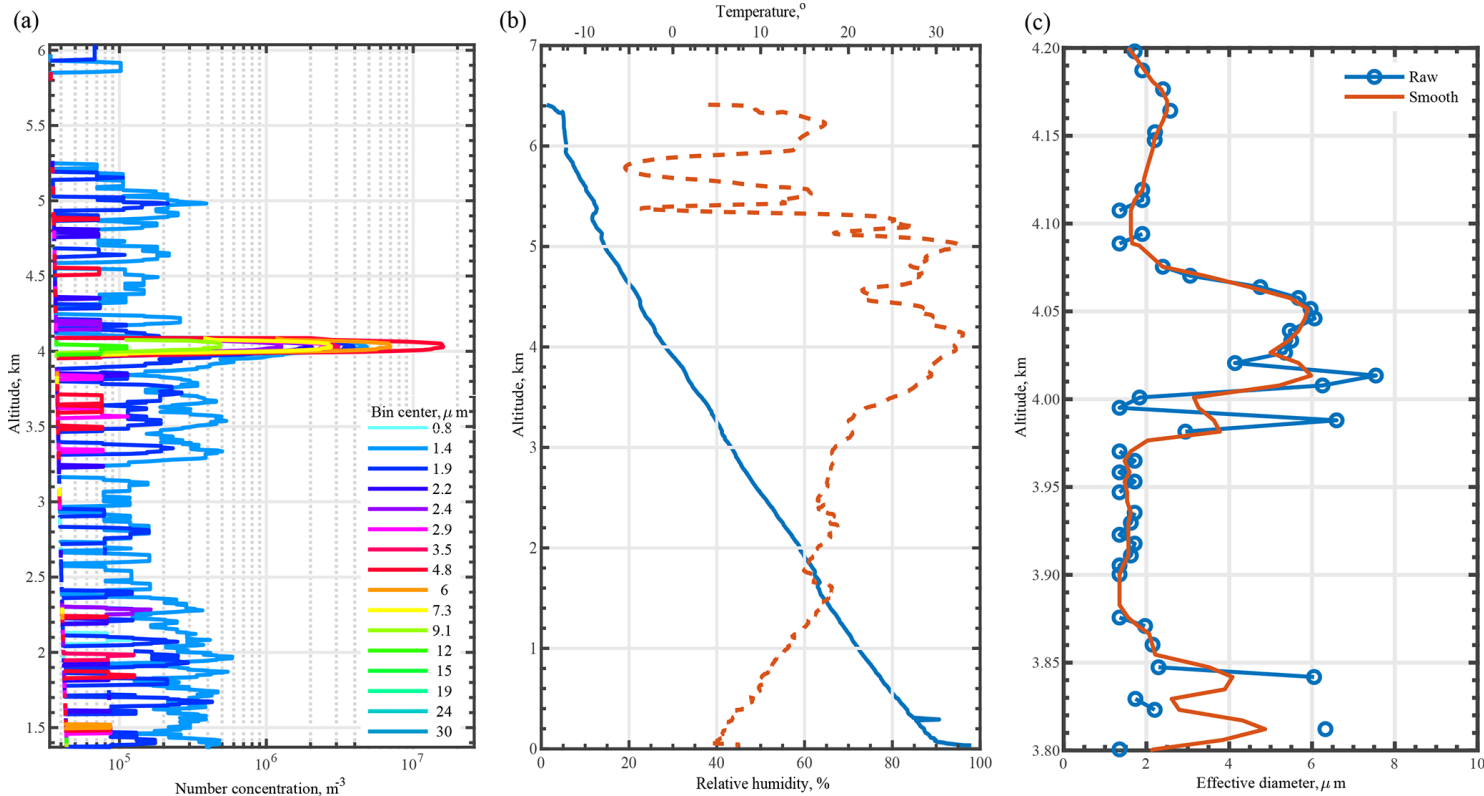

Figure 18. (a) Number concentration of particulates in the 16 UCASS size bins with respect to altitude, suggesting an embedded cloud layer at $4 \mathrm{~km}$. (b) Temperature and relative humidity profiles from the attached KITsonde, also suggesting an embedded cloud layer at $4 \mathrm{~km}$ with a spike in humidity. (c) Effective diameter with respect to altitude, the embedded cloud layer at $4 \mathrm{~km}$ is evident due to the steep increase in effective diameter. The blue line shows raw data, whilst the orange line shows smoothed data using a 10-point moving average.

fractive index, the geometric size is converted to a scattering cross section using Mie theory (Rosenberg et al., 2012), and the measured instrument response is plotted against the scattering cross section. For each unit, a relationship is found between the scattering cross section $\left(\sigma_{\text {sca }}\right)$ and instrument response (AD), in the form $\ln (\mathrm{AD})=a \ln \left(\sigma_{\mathrm{sca}}\right)+b$, where $a$ and $b$ are constants found through calibration measurements. By using a scattering cross section, rather than a geomet- ric diameter, this equation can be applied to particles of any refractive index or shape. Typically, the bin boundaries are chosen using a priori information on the particles being measured (i.e. mineral dust or water); however, with this relationship established, post calibrations can be applied easily if post factum information of the aerosol properties becomes available. Due to this, the UCASS can be used to measure in mixtures of cloud and aerosol (as discussed in Sect. 3.2.1), 
(a)

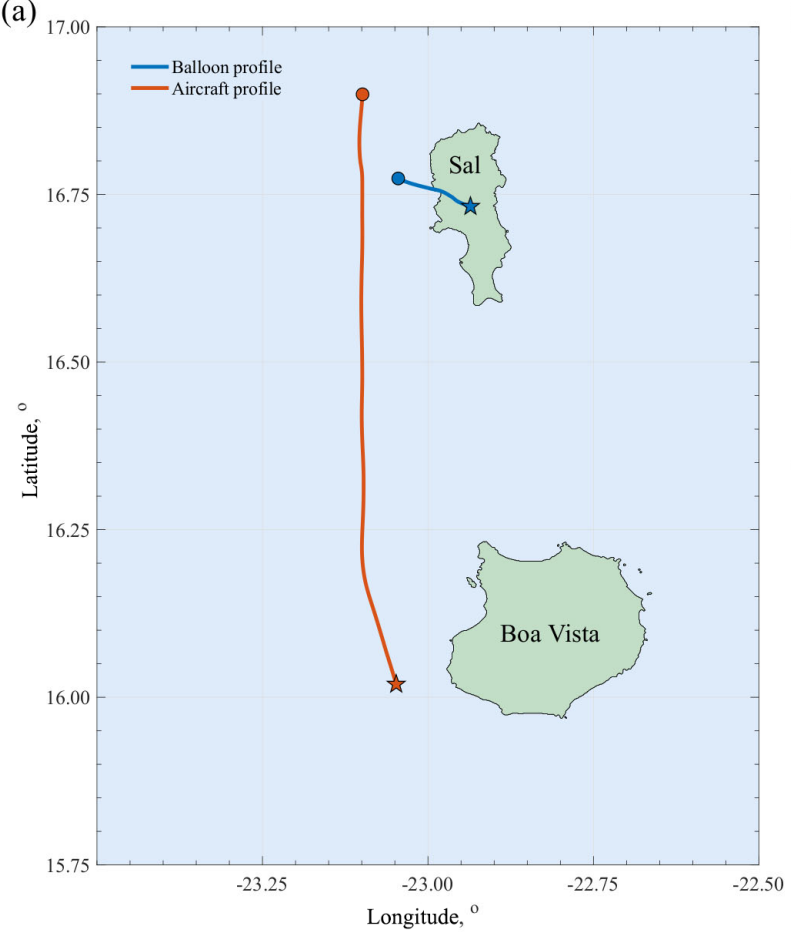

(b)

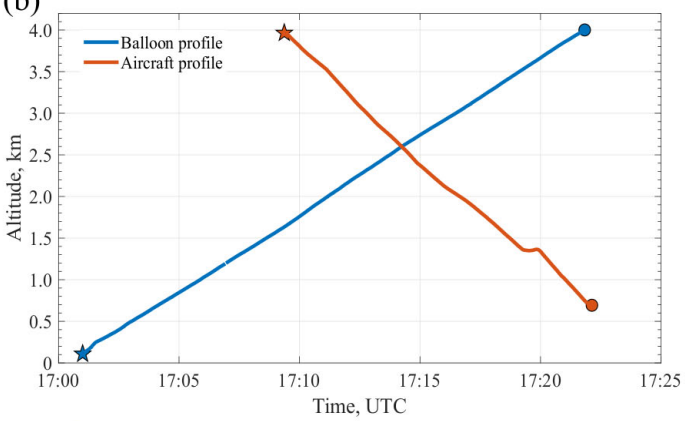

(c)

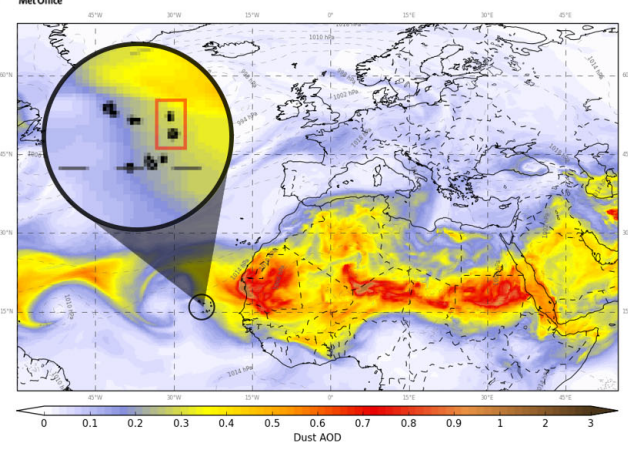

Figure 19. A balloon launch was conducted to coincide with profile 6 of SAVEX-D flight B934. Panel (a) shows the flights paths of the balloon (blue) and aircraft (orange) during this profile, where the start and end points are marked by stars and circles, respectively. The altitudes are shown in (b), whereby the aircraft descends from an altitude of $4 \mathrm{~km}$ to $690 \mathrm{~m}$. For comparative purposes, only the balloon data up to an altitude of $4 \mathrm{~km}$ are shown here. Panel (c) shows the MET office global atmosphere model aerosol optical depths (AODs) for 18:00 UTC. The Cabo Verde islands are zoomed-in and the islands of Sal and Boa Vista are highlighted in a red rectangle. It can be seen from this that the measurements were located to the edge of a dust layer, with an anticipated AOD of $\approx 0.3$.

(a)

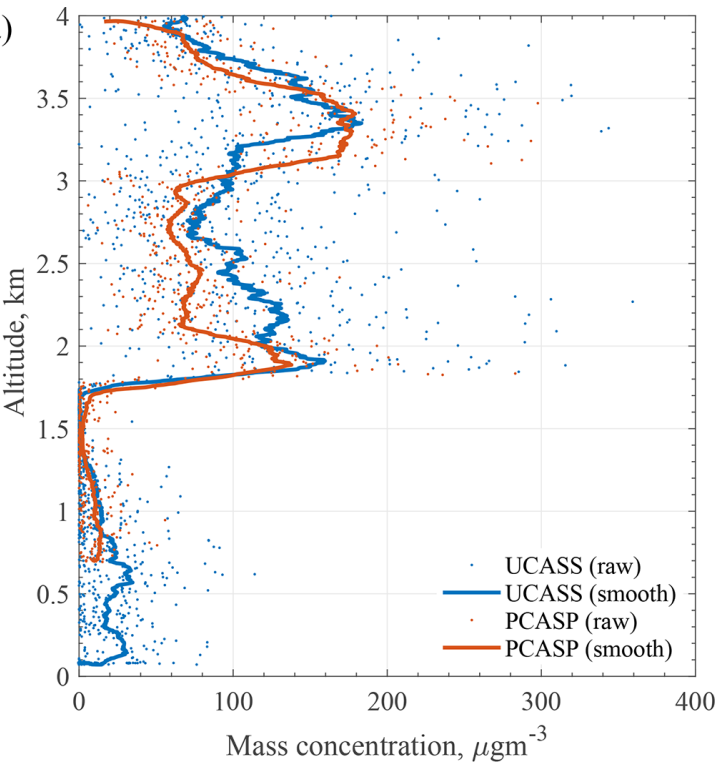

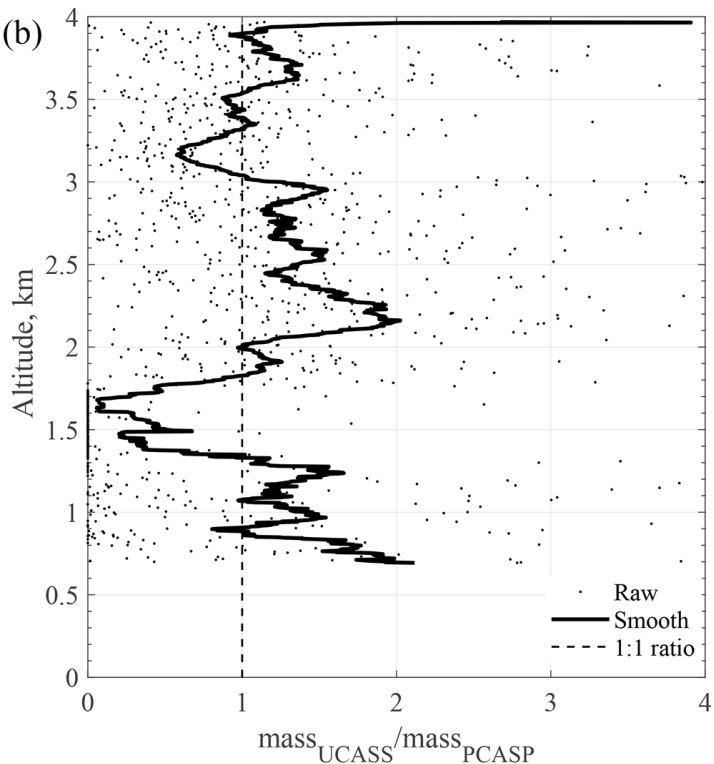

Figure 20. Panel (a) shows the measured mass concentrations with respect to altitude for the balloon-borne UCASS (blue) and aircraftmounted PCASP (orange). The raw data for each instrument are shown via individual data points, and the smoothed data are shown by a solid line, using a 10-point moving average. The mass concentrations shown pertain to particles within the $0.4-3 \mu \mathrm{m}$ size range for comparative purposes. Panel (b) shows the ratio of the UCASS-measured mass concentration to the PCASP-measured mass concentration. It can be seen that the largest differences occur at the top and bottom of the dust layer, which may be due to spatial variation and/or gravitational settling. 
where humidity profiles can be used to determine dry and cloudy air masses. The bin boundaries for different layers can then be modified for water or mineral dust accordingly.

The UCASS has been tested in a number of field-based and lab-based studies for the measurement of both aerosol and cloud droplets. During a Saharan dust episode in Magdeburg, Germany, the UCASS was used along with the KITsonde as a dropsonde system and dropped from the Dornier 128 research aircraft. The volume-size distribution measured by the UCASS shows good agreement with the AERONET inversion conducted at Leipzig, $100 \mathrm{~km}$ south-south-east of Magdeburg. The UCASS has also been tested as an upsonde system during the AER-D/SAVEX-D campaign, conducted over Cabo Verde in 2015. The UCASS was interfaced with a GRAW DFM-09 and launched from Sal island, coincident with a SAVEX-D research flight conducted $80 \mathrm{~km}$ southsouth-west of the launch site. Comparisons of the mass concentration measurements from the UCASS and the aircraftmounted PCASP show that measurements from both instruments agreed to within $20 \%$. The largest discrepancies are associated with the top and bottom of the dust layer, as anticipated from model results, which show the profiles were conducted near the edge of the dust layer, leading to spatial heterogeneity. For more controlled tests, the UCASS was tested in a wind tunnel at Observatoire de Physique du Globe de Clermont-Ferrand (OPGC) observatory, Puy De Dôme, during a stratocumulus event. The UCASS was co-located with a CDP-2 with a spatial separation of $<0.5 \mathrm{~m}$. The two instruments are designed for measurement in different ambient air speeds but in the overlapping range (10-15 $\left.\mathrm{m} \mathrm{s}^{-1}\right)$, the liquid water content measurements from the UCASS and CDP agree within $2 \%$.

Code and data availability. The AERONET data used in Fig. 17 are available online via the AERONET site: https://aeronet.gsfc. nasa.gov/ (last access: February 2019). PCASP data used in Fig. 20 are taken from SAVEX-D flight B934, access to this dataset can be requested through the Centre for Environmental Data Analysis (CEDA) and is archived at CEDA/Data Server/badc/ice-d/data/bae146/b934-2015-aug-25. CDP data used in Fig. 16 were provided by OPGC and are not publicly available. All UCASS data, plot data and analysis code can be made available upon request by contacting the lead author.

Author contributions. The original draft of the paper was prepared by HRS and reviewed and edited by all co-authors. Funding was obtained by ZU (NERC grants) and HRS (Aerosol Society small research grant, Trans-National Access grant). The project was conceptualized by ZU, PHK, EH, WS, RK and HRS. Investigations were conducted by HRS, ZU, AW, MK, RM and JG. Formal analysis and data curation were performed by HRS, ZU and JG. HRS, ZU, PHK, CS, RK, WS, MK, RG and JG contributed to the methodology. Software was provided by WS.
Competing interests. The authors declare that they have no conflict of interest.

Acknowledgements. The authors would like to thank all of our collaborators for aiding in the completion of this project. CDP data were provided by staff at OPGC and TROPOS. The inversions used in Fig. 17 were provided by AERONET; we thank Albert Ansmann for his efforts in establishing and maintaining the AERONET Leipzig site. The Met Office provided near-real-time forecast imagery for the AER-D/SAVEX-D campaign as used in Fig. 20. Airborne data from AER-D/SAVEX-D were obtained using the BAe146-301 atmospheric research aircraft operated by Directflight Limited and managed by FAAM, which is a joint entity of NERC and the Met Office.

Financial support. This work was supported by grants from the Natural Environment Research Council (NERC) (grant nos. NE/L002809/1 and CC0030), alongside a small research grant from the Aerosol Society. Experiments at the Puy de Dôme observatory were supported by a Trans-National Access (TNA) grant through the ACTRIS-2 initiative.

Review statement. This paper was edited by Troy Thornberry and reviewed by James Dorsey, Masatomo Fujiwara and one anonymous referee.

\section{References}

Bohren, C. F. and Huffman, D. R.: Absorption and scattering of light by small particles, Wiley-Interscience, New York, 1998.

Bokoye, A. I., Royer, A., O'Neill, N. T., and McArthur, L. J. B.: A North American Arctic aerosol climatology using ground-based sun photometry, Arctic, 55, 215-228, https://doi.org/10.14430/arctic706, 2002.

Cai, Y., Snider, J. R., and Wechsler, P.: Calibration of the passive cavity aerosol spectrometer probe for airborne determination of the size distribution, Atmos. Meas. Tech., 6, 2349-2358, https://doi.org/10.5194/amt-6-2349-2013, 2013.

Charlson, R. J., Seinfeld, J. H., Nenes, A., Kulmala, M., Laaksonen, A., and Facchini, M. C.: Reshaping the Theory of Cloud Formation, Science, 292, 2025-2026, https://doi.org/10.1126/science.1060096, 2001.

Che, H., Zhang, X., Chen, H., Damiri, B., Goloub, P., Li, Z., Zhang, X., Wei, Y., Zhou, H., Dong, F., Li, D., and Zhou, T.: Instrument calibration and aerosol optical depth validation of the China Aerosol Remote Sensing Network, J. Geophys. Res., 114, D03206, https://doi.org/10.1029/2008JD011030, 2009.

Chu, D. A., Kaufman, Y. J., Zibordi, G., Chern, J. D., Mao, J., Li, C., and Holben, B. N.: Global monitoring of air pollution over land from the Earth Observing System-Terra Moderate Resolution Imaging Spectroradiometer (MODIS), J. Geophys. Res., 108, D21, https://doi.org/10.1029/2002JD003179, 2003.

Dubovik, O. and King, M. D.: A flexible inversion algorithm for retrieval of aerosol optical properties from Sun and sky radiance 
measurements, J. Geophys. Res.-Atmos., 105, 20673-20696, https://doi.org/10.1029/2000JD900282, 2000.

Fujiwara, M., Sugidachi, T., Arai, T., Shimizu, K., Hayashi, M., Noma, Y., Kawagita, H., Sagara, K., Nakagawa, T., Okumura, S., Inai, Y., Shibata, T., Iwasaki, S., and Shimizu, A.: Development of a cloud particle sensor for radiosonde sounding, Atmos. Meas. Tech., 9, 5911-5931, https://doi.org/10.5194/amt-9-59112016, 2016.

Gao, R. S., Telg, H., McLaughlin, R. J., Ciciora, S. J., Watts, L. A., Richardson, M. S., Schwarz, J. P., Perring, A. E., Thornberry, T. D., Rollins, A. W., Markovic, M. Z., Bates, T. S., Johnson, J. E., and Fahey, D. W.: A light-weight, high-sensitivity particle spectrometer for $\mathrm{PM}_{2.5}$ aerosol measurements, Aerosol Sci. Technol., 50, 88-99, https://doi.org/10.1080/02786826.2015.1131809, 2016.

Hangal, S. and Willeke, K.: Aspiration Efficiency: Unified Model for All Forward Sampling Angles, Environ. Sci. Tech., 24, 688691, https://doi.org/10.1021/es00075a012, 1990.

Holben, B. N., Eck, T. F., Slutsker, I., Tanré, D., Buis, J. P., Setzer, A., Vermote, E., Reagan, J. A., Kaufman, Y. J., Nakajima, T., Lavenu, F., Jankowiak, I., and Smirnov, A.: AERONET - A federated instrument network and data archive for aerosol characterization, Remote Sens. Environ., 66, 1-16, https://doi.org/10.1016/S0034-4257(98)00031-5, 1998.

Huete, A.: Academic Press, Burlington, https://doi.org/10.1016/B978-012064477-3/50013-8, 2004.

IPCC: The Physical Science Basis: Contribution of Working Group 1 to the Fifth Assessment Report of the IPCC, Cambridge University Press, Cambridge, 2013.

Jiao, Z., Zhang, X., Bréon, F.-M., Dong, Y., Schaaf, C. B., Román, M., Wang, Z., Cui, L., Yin, S., Ding, A., and Wang, J.: The influence of spatial resolution on the angular variation patterns of optical reflectance as retrieved from MODIS and POLDER measurements, Remote Sens. Environ., 215, 371-385, https://doi.org/10.1016/j.rse.2018.06.025, 2018.

Kaufman, Y. J., Tanré, D., Remer, L. A., Vermote, E. F., Chu, A., and Holben, B. N.: Operational remote sensing of tropospheric aerosol over land from EOS moderate resolution imaging spectroradiometer, J. Geophys. Res.-Atmos., 102, 17051-17067, https://doi.org/10.1029/96JD03988, 1997.

Kerker, M.: The scattering of light and other electromagnetic radiation, Academic Press, Cambridge, Massachusetts, 1969.

Kokhanovsky, A. A., Deuzé, J. L., Diner, D. J., Dubovik, O., Ducos, F., Emde, C., Garay, M. J., Grainger, R. G., Heckel, A., Herman, M., Katsev, I. L., Keller, J., Levy, R., North, P. R. J., Prikhach, A. S., Rozanov, V. V., Sayer, A. M., Ota, Y., Tanré, D., Thomas, G. E., and Zege, E. P.: The inter-comparison of major satellite aerosol retrieval algorithms using simulated intensity and polarization characteristics of reflected light, Atmos. Meas. Tech., 3, 909-932, https://doi.org/10.5194/amt-3-909-2010, 2010.

Lance, S., Brock, C. A., Rogers, D., and Gordon, J. A.: Water droplet calibration of the Cloud Droplet Probe (CDP) and in-flight performance in liquid, ice and mixed-phase clouds during ARCPAC, Atmos. Meas. Tech., 3, 1683-1706, https://doi.org/10.5194/amt-3-1683-2010, 2010.

Lee, S.-C.: Dependent scattering of an obliquely incident plane wave by a collection of parallel cylinders, J. Appl. Phys., 68, 4952-4957, https://doi.org/10.1063/1.347080, 1990.
Li, Z., Lee, K.-H., Wang, Y., Xin, J., and Hao, W.-M.: First observation-based estimates of cloud-free aerosol radiative forcing across China, J. Geophys. Res.-Atmos., 115, D00K18, https://doi.org/10.1029/2009JD013306, 2010.

Loeb, N. G., Wiwelicki, B. A., Doelling, D. R., Smith, G. L., Keyes, D. F., Kato, S., Manalo-Smith, N., and Wong, T.: Toward optimal closure of the Earth's top-of-atmosphere radiation budget, J. Climate, 22, 748-766, https://doi.org/10.1175/2008JCLI2637.1, 2009.

Marenco, F., Ryder, C., Estellés, V., O’Sullivan, D., Brooke, J., Orgill, L., Lloyd, G., and Gallagher, M.: Unexpected vertical structure of the Saharan Air Layer and giant dust particles during AER-D, Atmos. Chem. Phys., 18, 17655-17668, https://doi.org/10.5194/acp-18-17655-2018, 2018.

Martin, G. M., Brooks, M. E., Johnson, B., Milton, S. F., Webster, S., Jayakumar, A., Mitra, A. K., Rajan, D., and Hunt, K. M. R.: Forecasting the monsoon on daily to seasonal time-scales in support of a field campaign, Q. J. Roy. Meteorol. Soc., 1-22, https://doi.org/10.1002/qj.3620, 2019.

Mishra, A. K., Koren, I., and Rudich, Y.: Effect of aerosol vertical distribution on aerosol-radiation interaction: A theoretical prospect, Heliyon, 1, e00036, https://doi.org/10.1016/j.heliyon.2015.e00036, 2015.

Myhre, G., Samset, B. H., Schulz, M., Balkanski, Y., Bauer, S., Berntsen, T. K., Bian, H., Bellouin, N., Chin, M., Diehl, T., Easter, R. C., Feichter, J., Ghan, S. J., Hauglustaine, D., Iversen, T., Kinne, S., Kirkevåg, A., Lamarque, J.-F., Lin, G., Liu, X., Lund, M. T., Luo, G., Ma, X., van Noije, T., Penner, J. E., Rasch, P. J., Ruiz, A., Seland, Ø., Skeie, R. B., Stier, P., Takemura, T., Tsigaridis, K., Wang, P., Wang, Z., Xu, L., Yu, H., Yu, F., Yoon, J.-H., Zhang, K., Zhang, H., and Zhou, C.: Radiative forcing of the direct aerosol effect from AeroCom Phase II simulations, Atmos. Chem. Phys., 13, 1853-1877, https://doi.org/10.5194/acp13-1853-2013, 2013.

Ramanathan, V., Crutzen, P. J., Kiehl, T., and Rosenfeld, D.: Aerosols, Climate, and the Hydrological Cycle, Science, 294, 2119-2124, https://doi.org/10.1126/science.1064034, 2001.

Renard, J.-B., Dulac, F., Berthet, G., Lurton, T., Vignelles, D., Jégou, F., Tonnelier, T., Jeannot, M., Couté, B., Akiki, R., Verdier, N., Mallet, M., Gensdarmes, F., Charpentier, P., Mesmin, S., Duverger, V., Dupont, J.-C., Elias, T., Crenn, V., Sciare, J., Zieger, P., Salter, M., Roberts, T., Giacomoni, J., Gobbi, M., Hamonou, E., Olafsson, H., Dagsson-Waldhauserova, P., Camy-Peyret, C., Mazel, C., Décamps, T., Piringer, M., Surcin, J., and Daugeron, D.: LOAC: a small aerosol optical counter/sizer for ground-based and balloon measurements of the size distribution and nature of atmospheric particles - Part 1: Principle of measurements and instrument evaluation, Atmos. Meas. Tech., 9, 1721-1742, https://doi.org/10.5194/amt-9-1721-2016, 2016.

Rosenberg, P. D., Dean, A. R., Williams, P. I., Dorsey, J. R., Minikin, A., Pickering, M. A., and Petzold, A.: Particle sizing calibration with refractive index correction for light scattering optical particle counters and impacts upon PCASP and CDP data collected during the Fennec campaign, Atmos. Meas. Tech., 5, 1147-1163, https://doi.org/10.5194/amt-5-1147-2012, 2012.

Schäfer, J., Lee, S.-C., and Kienle, A.: Calculation of the near fields for the scattering of electromagnetic waves by multiple infinite cylinders at perpendicular incidence, J Q. Spectrosc. Ra., 113, 2113-2123, https://doi.org/10.1016/j.jqsrt.2012.05.019, 2012. 
Schäfer, J.-P.: Implementierung und Anwendung analytischer und numerischer Verfahren zur Lösung der Maxwellgleichungen für die Untersuchung der Lichtausbreitung in biologischem Gewebe, available at: http://vts.uni-ulm.de/doc.asp?id=7663 (last access: February 2019), 2011.

Spiegel, J. K., Zieger, P., Bukowiecki, N., Hammer, E., Weingartner, E., and Eugster, W.: Evaluating the capabilities and uncertainties of droplet measurements for the fog droplet spectrometer (FM-100), Atmos. Meas. Tech., 5, 2237-2260, https://doi.org/10.5194/amt-5-2237-2012, 2012.

Storelvmo, T.: Uncertainties in aerosol direct and indirect effects attributed to uncertainties in convective transport parameterizations, Atmos. Res., 118, 357-369, https://doi.org/10.1016/j.atmosres.2012.06.022, 2012.

Twomey, S.: The Influence of Pollution on the Shortwave Albedo of Clouds, J. Atmos. Sci., 34, 1149-1152, https://doi.org/10.1175/1520-0469, 1977.

von der Weiden, S.-L., Drewnick, F., and Borrmann, S.: Particle Loss Calculator - a new software tool for the assessment of the performance of aerosol inlet systems, Atmos. Meas. Tech., 2, 479-494, https://doi.org/10.5194/amt-2-479-2009, 2009.
Vuolo, M. R., Schulz, M., Balkanski, Y., and Takemura, T.: A new method for evaluating the impact of vertical distribution on aerosol radiative forcing in general circulation models, Atmos. Chem. Phys., 14, 877-897, https://doi.org/10.5194/acp-14-8772014, 2014.

Wieser, A., Hinze, G., Franke, H., Schell, D., Schmidmer, F., and Kottmeier, C.: KITsonde - A novel modular MultiSensor Dropsonde System for High Resolution Measurements, available at: http://www.imk-tro.kit.edu/download/KITsonde_ posterDINA0_IMK.pdf (last access: February 2019), 2014.

Zhang, J. and Christopher, S. A.: Longwave radiative forcing of Saharan dust aerosols estimated from MODIS, MISR, and CERES observations on Terra, Geophys. Res. Lett., 30, 17051-17067, https://doi.org/10.1029/2003GL018479, 2003.

Zhou, Y. and Savijärvi, H.: The effect of aerosols on long wave radiation and global warming, Atmos. Res., 135-136, 102-111, https://doi.org/10.1016/j.atmosres.2013.08.009, 2014. 